\title{
Archaeological geophysics in Israel: past, present and future
}

\author{
L. V. Eppelbaum \\ Dept. of Geophysics and Planetary Sciences, Raymond and Beverly Sackler Faculty of Exact Sciences, Tel Aviv University, \\ Ramat Aviv 69978, Tel Aviv, Israel
}

Received: 4 February 2010 - Revised: 1 March 2010 - Accepted: 11 March 2010 - Published: 9 April 2010

\begin{abstract}
In Israel occur a giant number of archaeological objects of various age, origin and size. Different kinds of noise complicate geophysical methods employment at archaeological sites. Geodynamical active, multi-layered, and geologically variable surrounding media in many cases damages ancient objects and disturbs their physical properties. This calls to application of different geophysical methods armed by the modern interpretation technology. The main attention is focused on the geophysical methods most frequently applying in Israeli archaeological sites: GPR and high-precise magnetic survey. Other methods (paleomagnetic, resistivity, near-surface seismics, piezoelectric, etc.) are briefly described and reviewed. The number of employed geophysical methodologies is constantly increasing, and now Israeli territory may be considered as a peculiar polygon for various geophysical methods testing. Several examples illustrate effective application of geophysical methods over some typical archaeological remains. The geophysical investigations at archaeological sites in Israel could be tentatively divided on three stages: (1) past (1990), (2) present (19902009), and (3) future (2010). The past stage with several archaeoseismic reviews and very limited application of geophysical methods was replaced by the present stage with the violent employment of numerous geophysical techniques. It is supposed that the future stage will be characterized by extensive development of multidiscipline physicalarchaeological databases, employment of all possible indicators for 4-D monitoring and ancient sites reconstruction, as well as application of combined geophysical multilevel surveys using remote operated vehicles at low altitudes.
\end{abstract}

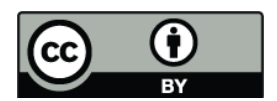

Correspondence to: L. Eppelbaum (levap@ post.tau.ac.il)

\section{Introduction}

The territory of Israel, in spite of its comparatively small dimensions (about of $22000 \mathrm{~km}^{2}$ ), contains extremely large number of archaeological remains due to its rich ancient and Biblical history (map with location of several archaeological sites displayed in this article, is presented in Fig. 1). Many authors (e.g., Kenyon, 1979; Kempinski and Reich, 1992; Meyers, 1996) note that the density location of archaeological sites on Israeli territory is the highest in the world. Geophysical methods are applied for the revealing and localization of archaeological remains as rapid, effective and noninvasive tools for the study of a broad range of various targets in Israel (e.g., Ginzburg and Levanon, 1977; Dolphin, 1981; Witten et al., 1994; Itkis and Eppelbaum, 1998; BenDor et al., 1999; Sternberg et al., 1999; Ezersky et al., 2000; Eppelbaum et al., 2001b, 2003, 2006a, b, 2008, 2010b; Eppelbaum and Itkis, 2003; Itkis et al., 2003; Weinstein-Evron et al., 2003; Boyce et al., 2004; Jol et al., 2008).

Application of geophysical methods has a great potential due to their different physical principles and varied scales of survey, various locations of measuring sensors and different possible combinations of methods (processing and interpretation of geophysical data may also differ). Informational approach to archaeogeophysical data analysis permits to extract a maximum of useful information. Geophysical surveys provide a ground plan of cultural remains before excavations or may be even used instead of excavations. Road and plant construction, selection of areas for various engineering and agricultural aims are usually accompanied by detailed geophysical investigations. Rapid and reliable interpretation of geophysical data should provide protection of archaeological remains from unpremeditated destruction.

Among the variety of ancient objects in Israel, the most typical sites of different ages and origins (taking into account also a frequency of geophysical methods application), are presented in this paper. 


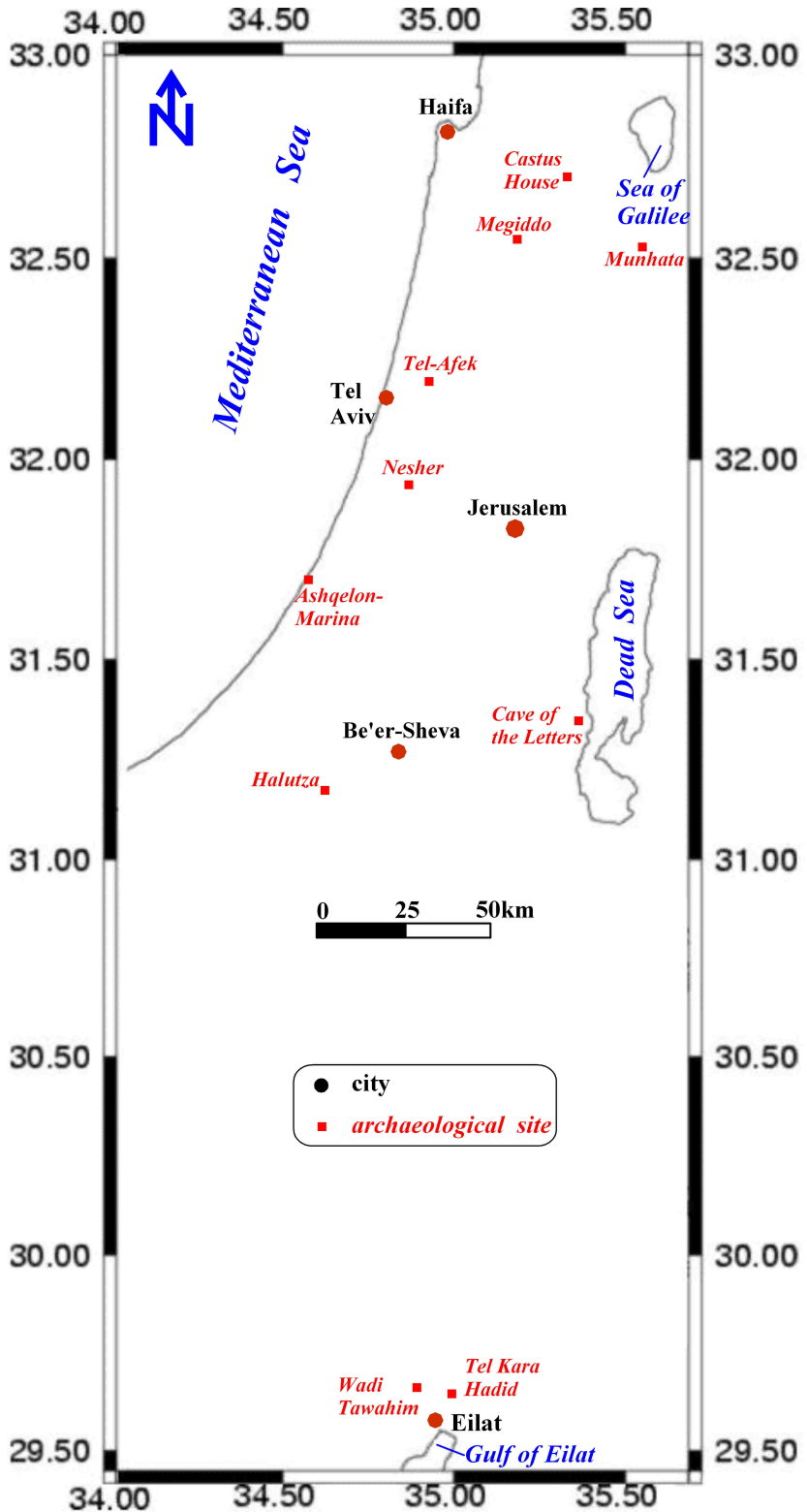

Fig. 1. Map of the area under study showing several sites mentioned in the paper.

At the same time, different kinds of noise complicate geophysical survey in Israel, and methods of the noise elimination (reducing) are of a great importance. The most typical noise factors in Israel are: damaging of ancient targets caused by the significant geodynamic activity, strong geological variability of the medium, and oblique magnetization (polarization).

\section{Archaeogeophysical target recognition: application of some basis components of informational theory}

All types of geophysical investigations are applied in the definite succession in time and space. In archaeogeophysics different physical means are employed, but even single physical tool application (e.g., GPR, magnetics, selfpotential method) may have different conditions (observation step, distance between profiles, accuracy, type of equipment, etc.). The final aim of archaeogeophysics employment is the best recognition (the most precise identification of targets) of studied archaeological site by some given limitations (Fig. 2).

The problem of geophysical tool(s) rational utilization could be solved using employment of the following criterions (on the basis of Eppelbaum et al., 2003):

(1) necessary expenditures for realization of the geophysical tool (cost criterion $\mathrm{C}$ ),

(2) necessary time for realization of the geophysical tool (time criterion $\mathrm{T}$ ),

(3) informativeness of the geophysical tool (informational criterion $\Pi$ ).

Criterions $\mathrm{C}$ and $\mathrm{T}$ can be easy determined by a direct calculation, but estimation of criterion $\Pi$ is a complex investigation problem.

In archaeology, often location of an ancient target relatively to surrounding medium might provide more significant information than the artifact alone (Bentley and Schneider, 2000). Therefore, all available archaeological/geological information can be represented in the classic three-level variant (Eppelbaum et al., 2003): (a) syntactical - number of information; (b) semantic - substance of information; (c) pragmatic - value of information.

A principal logical-heuristic model of the geophysical/archaeological information can be described in the following form:

$\Pi=Q \cup R \cup V$,

where $Q$ is the quantitative estimation of information, $R$ is the estimation of informational reliability corresponding to the semantic criterion, $V$ is the estimation of informational value by degree of aim achievement according to the pragmatic criterion, $\cup$ is the symbol of unification.

This algorithm is based on the fundamental terms of information theory and combined with the structural (hierarchical) approach. This approach allows to construct each geophysical indicator as a structure reflecting a set of typical situations. After this the depth of searching recognition is estimated and calculated using informational approach. Realization of the proposed strategy provides effective analysis of near-surface/environmental studies and development of reliable physical-archaeological models (PAMs). In real 


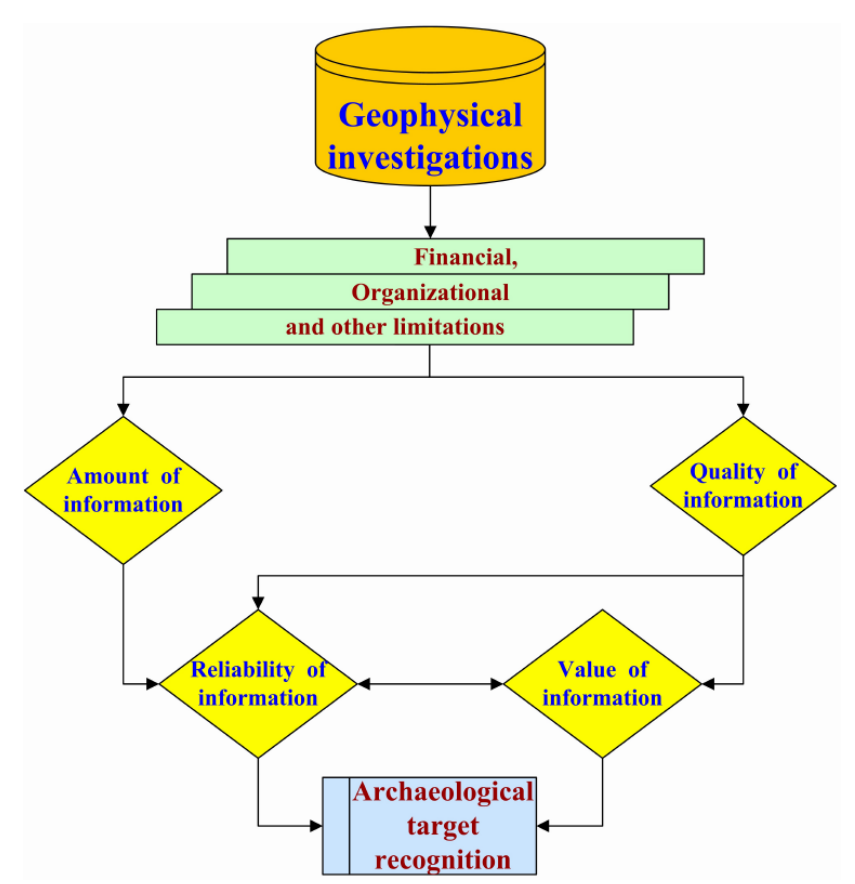

Fig. 2. A scheme of archaeogeophysical target recognition with elements of information theory (on the basis of Eppelbaum et al. (2003), with modification).

conditions many random factors disturb the results obtained by a set of archaeological-geophysical means. One of the essential problems consists of impossibility to obtaining satisfactory formalized description of factors influencing the results of local determinations. The similar situations are known in the theory of "decision making" where a full mathematical formalization of the investigated problem is complicated. Our experience (Eppelbaum and Eppelbaum, 1995; Eppelbaum et al., 2001b, 2003) allows us to suggesting that application of expert methods in many situations (set of logical and math-statistical procedures) will be most effective one. Performed analysis permits to conclude that increment of reliability of archaeogeophysical and related tools especially depends on number of the tools involving to prospecting set and their reliabilities, and on method of the tools integration.

\section{Noise complicating geophysical investigations in archaeological sites in Israel}

Geophysical observations at archaeological sites in Israel are complicated by numerous factors (Eppelbaum and Khesin, 2001; Eppelbaum et al., 2001b, 2006b) (Fig. 3). These disturbances are briefly considered below.

\subsection{Artificial noise}

The Industrial component comprises power-lines, cables, buildings, different underground and transport communications and strongly affects practically all physical fields applied in archaeogeophysics (to a lesser degree - piezoelectric and self-potential (SP) methods). The Instrumental component is associated with the technical properties of geophysical instruments (e.g., "shift zero" of gravimeters and accomplishing electrode's noise in SP) and their spatial location. Human mistakes, unfortunately, will accompany geophysical observations some more time. Difficulties of electrode grounding are of some significance in geophysical prospecting with the electrode system of measurements, such as resistivity, vertical electric sounding (VES) and SP methods (geophone grounding - for seismic and piezoelectric methods). The last component of artificial noise is the absence of information about previous archaeological excavations at the site under study that does not allow utilization of these data for planning geophysical investigations and their analysis.

\subsection{Natural disturbances}

The first component of nonstationary noise comprises temporary variations in geophysical fields, such as tidal variations in the gravity field, ionosphere disturbances influencing magnetic and electromagnetic Very Low Frequency (VLF) fields and climatic changes affecting the SP field and near-surface temperature observations. A second component of nonstationary noise reflects meteorological conditions (rain, lightning, snow, hurricanes, etc.) obviously disturbing observations in all geophysical methods. Soil-vegetation factors are associated with some soil types (e.g., water-logged ground or loose ground in deserts) and dense vegetation complicates accessibility of geophysical equipment. Uneven terrain relief causes technical limitations for equipment transportation and geophysical data measurements. Physically this disturbance is generally two-fold for potential and quasi-potential fields: first, there is the effect of the form and physical properties of the topographic bodies forming the relief and, secondly, there is the effect of variations in the distance from the measurement point to the hidden target (Khesin et al., 1996). Uneven relief also strongly distorts ground penetrating radar (GPR), VES and seismic observations.

\subsection{Geological-geophysical and archaeological factors}

There are the most important physical-archaeological disturbances. First of all, is necessary to note that Physical limitation of method application reflects some physical properties of the geoarchaeological section (for example, watering of the section does not allow to use effectively electric, electromagnetic and temperature methods, etc.). The Ancient earthquake damages are widely identified in Israel (especially in the regions closely disposed to the Dead Sea Transform 


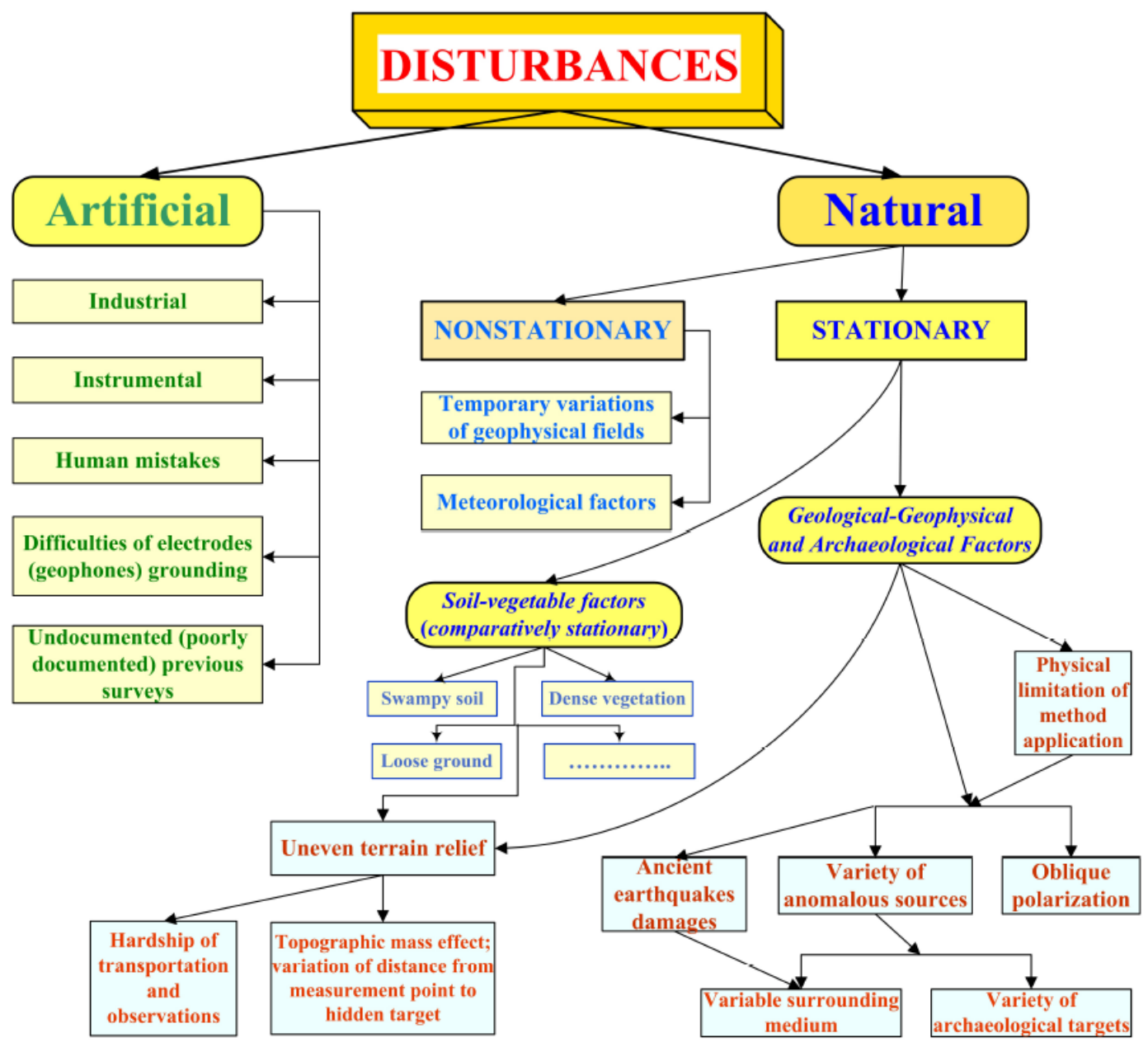

Fig. 3. Archaeological geophysics: classification of disturbing factors (after Eppelbaum et al., 2001b; 2010b, revised and supplemented).

Zone). The Variety of anomalous sources is composed of two factors: variable surrounding medium and variety of archaeological targets. Both these factors are very crucial and strongly complicate interpretation of all geophysical fields.

\subsection{Oblique polarization}

Oblique magnetization (polarization) complicates such geophysical fields as magnetic, VLF, SP, thermal, resistivity and piezioelectric. Oblique polarization disturbs these geophysical fields in the following manner: the major extremum is shifted from the projection of the upper edge of the object on the plan, and an additional extremum may appear (Khesin et al., 1996). It should be noted that oblique magnetization is the characteristic peculiarity for Israel due to its geographical location.

\subsection{On the correlation between the useful signal and noise}

In many cases it is assumed that the noise is normally distributed and not correlated to the geophysical signal. Analysis of geophysical data indicates that these assumptions often do not obeyed. For example, a principal scheme of wideband noise Kalman filtering in geophysics is considered in (Bashirov et al., 1992).

As it was noted in Eppelbaum (1989), sometimes a correlation between the useful signal and dispersion of noise is observed. In this case a cross-correlation function $B_{\mathrm{sn}}$ between the signal and noise may be presented as

$B_{\mathrm{sn}}(m)=E\left[\left(S_{m}-E\left(S_{m}\right)\right)\left(n_{m}-E\left(n_{m}\right)\right)\right]$,

where $E$ is the statistical expectation, $S_{m}$ and $n_{m}$ are the expected signal and noise, respectively.

Equation (2a) may be rewritten as

$B_{\mathrm{sn}}(m)=E\left[S_{m}\left(n_{m}-E\left(n_{m}\right)\right)\right]$. 
In consideration of the properties of the dispersion as a random quantity (e.g., Triola, 2007), Eq. (2b) is transformed as

$B_{\text {sn }}(m)=E\left[S_{m}\left(n_{m}-E\left(n_{m}\right) \pm \sqrt{D_{n}^{2}}\right)\right]$,

where $D_{n}$ is the dispersion.

Taking into account that

$E\left[S_{m}\left(n_{m}-E\left(n_{m}\right)-\sqrt{D_{n}^{2}}\right)\right]=0$,

Eq. (2b) may be represented in the following form

$B_{\mathrm{sn}}(m)=E\left(S_{m} \sqrt{D_{n}^{2}}\right)$.

Thus, cross-correlation function between the useful signal and noise dispersion may be described by the use of Eq. (4). Such relationship between the signal and noise permits to utilize these peculiarities in the corresponding PAM.

\section{Archaeoseismic investigations}

Taking into account that Israel is situated within the geodynamically active zone, seismo-archaeological investigations occupy a significant place in the total geophysicalarchaeological mosaic in Israel. Apparently, seismoarchaeological investigations were first geophysical investigations in the Holy Land in the past (Willis, 1928). Shalem (1949) has lighted earthquakes in Jerusalem from the ancient period to the middle of XX century. Karcz et al. (1977) and Karcz and Kafri (1978) noted that the most part of the ancient damaged constructions lie within or near to the Dead Sea Transform Zone and developed some classification of the ancient earthquakes. Ben-Menahem (1979) has created an earthquake catalogue for the Middle East (92 BC-1980 AD). Seismo-archaeological examination oriented to detecting and catalogue of ancient earthquakes was successfully carried out at several Israeli archaeological sites (for instance, Marco et al., 1996; Ellenblum et al., 1998; Marco et al., 2003). Detailed studying of damage features observed in the ancient ruins of the Avdat archeological site (Negev Desert, Israel) permitted to identify the seismic origin of the destruction and to determine roughly the direction of seismic wave propagation (Korjenkov and Mazor, 1999). Nur and Ron (1997) investigated in detail the Armageddon's (Megiddo) earthquakes in the Northern Israel. Kamai and Hatzor (2007) proposed to apply a discontinuous deformation analysis to estimate historic ground motions. A fragment of comprehensive collage presented in Marco (2008) illustrates various damages of ancient constructions caused by geodynamic events in Northern Israel (Fig. 4). An integrated analysis of these damages permits not only to develop seismological pattern for the different periods of past, but also helps to create reliable PAMs of different ancient targets.

\section{Ground penetrating radar}

High-resolution ground penetrating radar (GPR) surveys are widely applied in Israel for solving different archaeological problems. Apparently, GPR was firstly applied in Israel for the examination of some ancient constructions in the Old City of Jerusalem (Dolphin, 1981). Detailed GPR investigations at the site of Sepphoris (Galilee, Northern Israel) were used for the localization of many subsurface ancient features (Batey, 1987). GPR subsurface visualization extended the horizons of the well-known Qumran site (Dead Sea area, Israel) (Jol et al., 2003; Treague et al., 2005). GPR survey (integrated with remote sensing examination) has been effectively applied for mapping of ancient drainage system in the northern Negev (Southern Israel) (Blumberg et al., 2004).

An application of GPR survey at the Cave of the Letters, located in the tectonically active Dead Sea Transform Zone (Fig. 1) is of high interest. This archaeological site is a limestone cave whose Roman deposits have yielded a priceless collection of archaeological artifacts - pottery, coins and bronze objects, as well as 70 documents of this epoch including "Bar-Kokhba's letters" (Reeder et al., 2004). The cave served as a refuge for Jewish commanders and their families, towards the end of the Second Jewish Revolt against the Romans ( $\sim 135 \mathrm{BC})$. The cave floor is covered with roof fall that obscures the underlying archaeological deposits. A GPR survey was used in the interpretation and reconstruction of living surfaces below the roof fall. As part of the GPR analysis, a three-dimensional data set was collected from a $5.5 \mathrm{~m} \times 2.5 \mathrm{~m}$ grid in Hall "B" of the cave (Fig. 5). 3-D data sets of such PAMs greatly aid in interpreting the framework of the subsurface materials and provide a more detailed view of the geometry of individual units (Reeder et al., 2004).

GPR imaging was very successfully applied for identification of archaeological features in the Cactus House and several adjacent sites in Nazareth (Northern Israel) (Jol et al., 2004, 2008). Results of GPR survey archaeological features occurring beneath the present floor of the Cactus House (Fig. 1) are presented in Fig. 6 (after Jol et al., 2008). 3-D cubes were assembled from a series of identical length 2-D GPR profiles running parallel to each other along an $x-y$ grid system within the tea-room and oven room. The cubes provide further evidence of the above interpretations. The reflections below the present floor in the Cactus House can indicate that the upper bath house was built upon an earlier bath house that more closely aligns with the water system located and excavated at the adjacent Mary's Well site.

An example of non-conventional GPR data analysis by the use of multifocusing seismic processing (MFSP) was displayed in Berkovitch et al. (2000). A MSFP is based on the homeomorphic imaging theory and consists of stacking seismic data with arbitrary source-receiver distribution according to a new local moveout correction. Three-parameter travel time representation permits to obtain a precise approximation for the full multi-coverage travel time surfaces. 

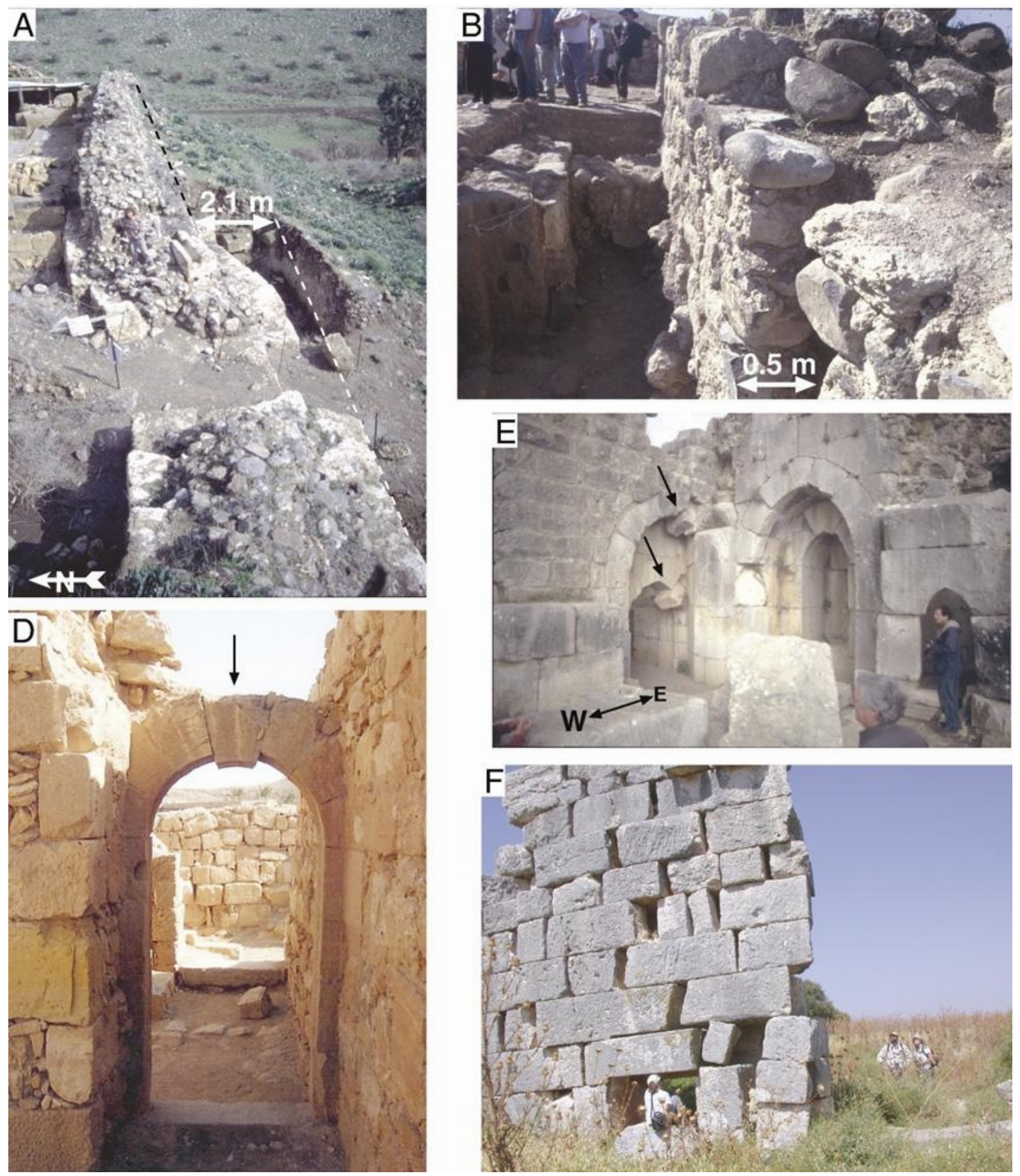

Fig. 4. (A) An offset wall of the Crusader fortress of Vadum Iacob. Dashed line shows original geometry. The 2.1-m-offset is the sum of $1.6 \mathrm{~m}$ and $0.5 \mathrm{~m}$ displacement caused by the earthquakes of 20 May 1202 and 30 October 1759, respectively. (B). An offset wall of the Ottoman Mosque that is built on top of the Crusader fortress of Vadum Iacob. The associated earthquake occurred on October 30, 1759 (C). A water trough in Um el Kanatir left-laterally offset about $1 \mathrm{~m}$ on the margin of a landslide triggered by the earthquake of $18 \mathrm{January} 749$ (D). A keystone slid down in an arch enclosed symmetrically by a wall (photographed in Mampsis) (E). Blocks on the sides of arches on the left slid down in the earthquake of 1759 in Kal'at Nimrod. Throughout the site, arches in walls that trend E-W are deformed whereas similar arches in N-S trending walls have remained intact $(\mathbf{F})$. Horizontal shift of large ashlars in the Hellenistic temple of Kadesh (site occurred in the 749 earthquake). All these sites occur in Northern Israel (after Marko, 2008). 


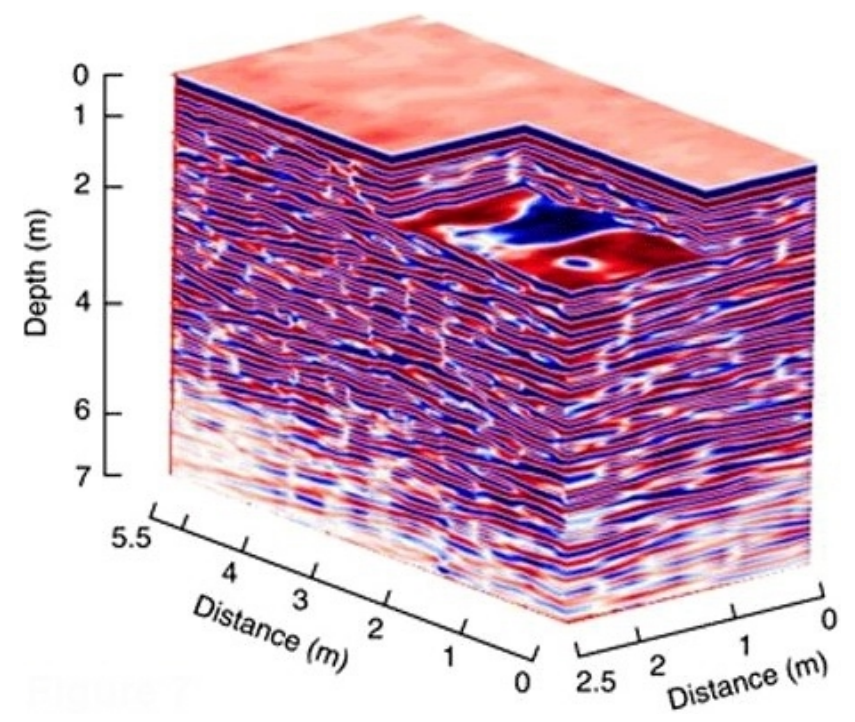

Fig. 5. GPR survey at the Cave of Letters (Dead Sea): 3-D cube with electric resistivity tomography lines and archaeological cave floor exposed (after Reeder et al., 2004).

Interestingly, that MF technology has multi-dimension orientation and may be successfully applied in other physical domains (Berkovitch and Eppelbaum, 2009). The proposed approach was tested in a well-studied geological section of the quarry "Nesher" in Central Israel (Fig. 1) near town of Ramla. In the nearest vicinity of this quarry (Fig. 7a) a lot of prehistoric targets was found. Length of the selected profile was $75 \mathrm{~m}$, step between the observation points $-0.25 \mathrm{~m}$, and distance between the source and receiver $-1.5 \mathrm{~m}$. Centre frequency was $100 \mathrm{MHz}$, time window $-0.83 \mathrm{~ns}$, and number of samples -1024 . Initial GPR section obtained by conventional method is shown in Fig. 7b and c illustrates application of the MF technology. It easy to see that upper part of the real geological section is more clearly presented in Fig. 7c than in Fig. 7b.

\section{Application of potential geophysical fields}

\subsection{Magnetic data analysis}

\subsubsection{Magnetic data transformation}

The magnetic method is one of the most widely used geophysical methods for recognition of buried archaeological targets. Sometimes, for removing the noise of different origin, distributed as quasi-white noise, it is useful to transform observed geophysical fields to some informational features. Eppelbaum (2001) and Eppelbaum et al. (2003a) proposed to

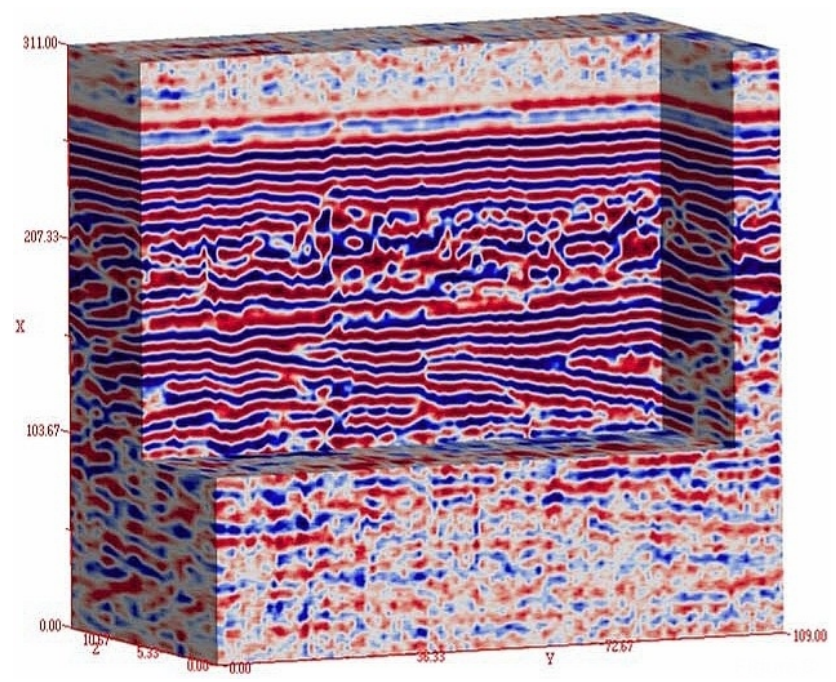

Fig. 6. GPR chair diagram of a 3-D cube collected in the tea room of the Cactus House. Where enough floor space was available parallel 2-D lines were collected to better understand the subsurface through 3-D perspectives (after Jol et al., 2008).

use the following expression:

$J_{i}=U_{i}\left(\sum_{i}^{n} U_{i}\right)^{-1} \log \left[U_{i}\left(\sum_{i}^{n} U_{i}\right)^{-1}\right] K$,

where $U_{i}$ is the geophysical observation at $i$ th point $\left(U_{i}>0\right)$ at the area under study, $n$ is the total number of observations, and $K$ is the some coefficient.

Let us consider converting of magnetic survey data, observed at the site of Munhata, to an informational parameter $J_{i}$. The site of Munhata is located on a terrace at the outlet of Nahal Tabor to the Jordan Valley, some $11 \mathrm{~km}$ south of Lake Kinneret, Northern Israel (Fig. 1), $215 \mathrm{~m}$ below sea level. The depth of archaeological remains at the Munhata site is between 2 and $3 \mathrm{~m}$. The magnetic survey at this site was expected to be successful taking into account the considerable contrast between features of interest (built mainly of different kinds of basalts) and dark brown surrounding soil. The magnetic survey was carried out to the north of the excavation area.

In the compiled magnetic map (Fig. 8a) it is difficult to reveal the anomalous objects, but this map processed by the use of Eq. (5) (Fig. 8b) clearly displays the desired objects (they outlined by white rectangular and circular frames). The known archaeological objects excavated to the south of the surveyed area are presented in Fig. 8c. Obviously, that archaeological targets shown in Fig. 8c (discovered objects) and informational images presented in Fig. 8c (proposed objects) have a good agreement. Thus, Fig. $8 \mathrm{~b}$ represents the simplest qualitative PAM. 

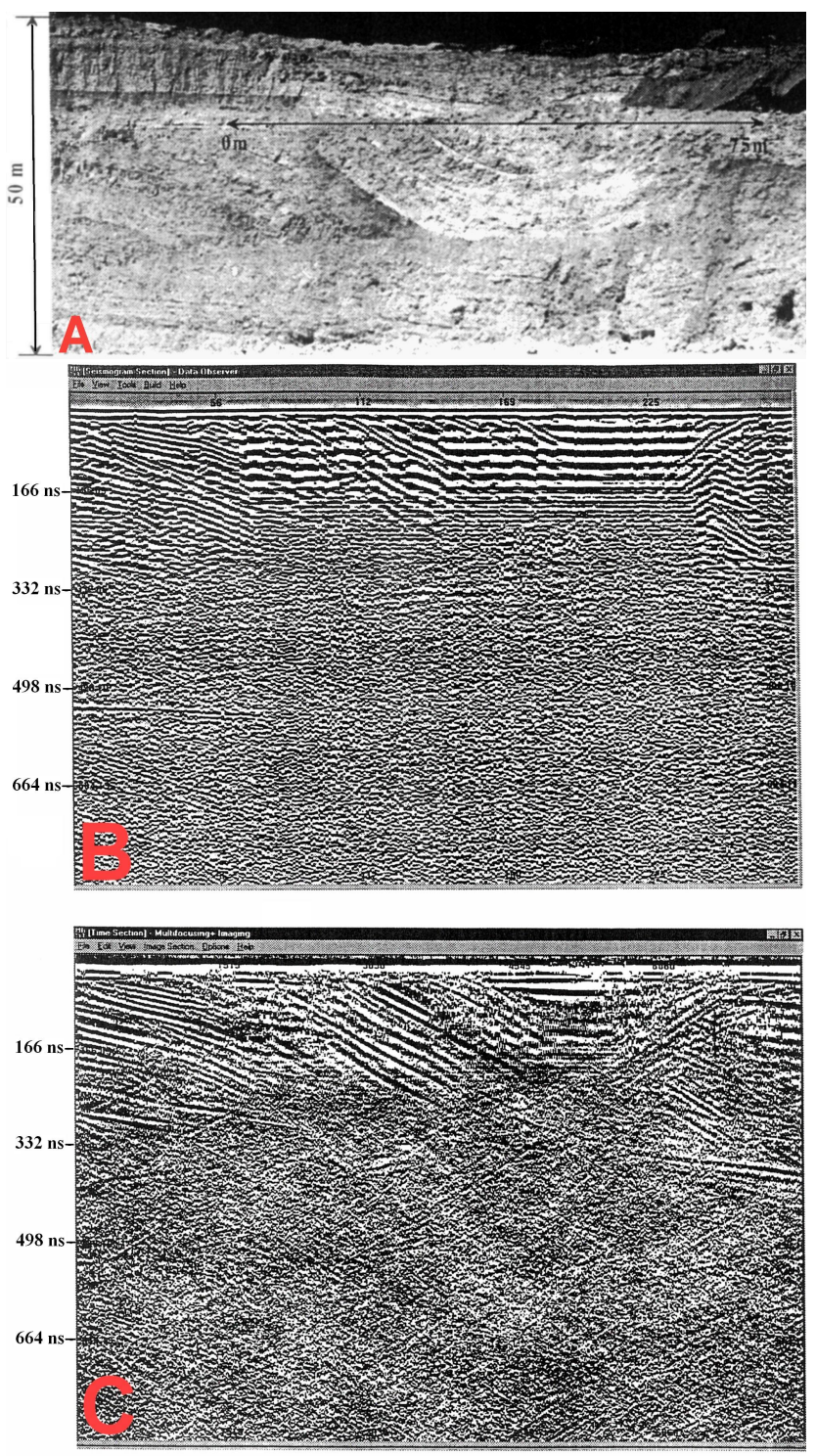

Fig. 7. (A) Photo of the geological section of a quarry "Nesher" (solid like in this section indicates location of the GRP profile). (B) Initial GPR section, (C) Multifocusing stack section (after Berkovitch et al., 2000).

\subsubsection{Quantitative analysis of magnetic anomalies in complex environments}

For quantitative analysis of magnetic anomalies, the following models usually are employed: thin bed (TNB), thick bed (TKB), horizontal circular cylinder (HCC) and horizontal plate (HP). These four models can be presented with various modifications (for instance, inclined upper and lower edges and inclined dipping), which practically cover all available major types of archaeological remains. For the TNB, TKB and $\mathrm{HCC}$, improved modifications of the characteristic point method, tangent method and areal method were developed (Khesin et al., 1996). They are relevant for the complex environments: oblique magnetization, rugged relief and an unknown level of the normal magnetic field. For the HP it was recognized that by a sizeable horizontal extension two arising anomalies might be interpreted independently (as specific TNB models) even in the mentioned complex environments (Eppelbaum, 2007).

A simple example of inverse problem solution for the model of buried archaeological cavity $(J=0)$ occurring in the magnetized medium $(J=300 \mathrm{~mA} / \mathrm{m})$ with underlying layer of $J=150 \mathrm{~mA} / \mathrm{m}$ is displayed in Fig. 9. Strong oblique magnetization $\left(44^{\circ}\right.$, typical for Israeli archaeological sites) and inclined surface relief complicate quantitative analysis of this anomaly. Simple visual analysis of the magnetic curve indicates that minimal amplitude of this anomaly might not coincide (see vertical green dash line) with the projection of hidden ancient object to the earth' surface. Application of the developed methodology of inverse problem solution (Khesin et al., 1996) permitted to determine the position of the sphere center (a model of horizontal circular cylinder was applied) with a high accuracy (Fig. 9). Hence, a trouble-free quantitative PAM has been constructed.

\subsubsection{Multimodel approach (on example of magnetic data examination)}

Quantitative interpretation of magnetic anomalies was traditionally oriented to a single model of buried objects identification. In the case of the existence of several hypotheses relating to the parameters of the body causing the disturbance (i.e. the buried object) usually only one model was selected roughly presenting the object in the domain $\Omega_{x}$ of $k$-dimensional space of physical-archaeological factors. At the same time, as a rule ancient remains are complicated objects broken by human and geodynamic activity as well as various geological/environmental processes. Additional noise affecting interpretation includes rugged terrain relief, oblique polarization of geological objects and archaeological remains, a heterogeneous host medium among other factors (see Sect. 2). As a consequence, response function $\Lambda_{i}$ - geophysical field - may ambiguously represent the ancient target. Therefore, domain $\Omega_{x}$ may be divided into several subdomains $\Omega_{1}, \ldots \Omega_{m}$ and in each of them a single model will dominate (Eppelbaum, 2005). In such a way we could develop $m$ physical-archaeological models of the same target, each corrected for separate subdomain $\Omega_{1}, \ldots \Omega_{m}$. For instance, remain of ancient wall in definite geological conditions may be recognized as TKB (magnetic field), sphere (gravity field) and HP (resistivity). The multimodel approach may also be realized at varying levels of geophysical field registration. As a result, different models of explanation may be used in the process of quantitative interpretation. 

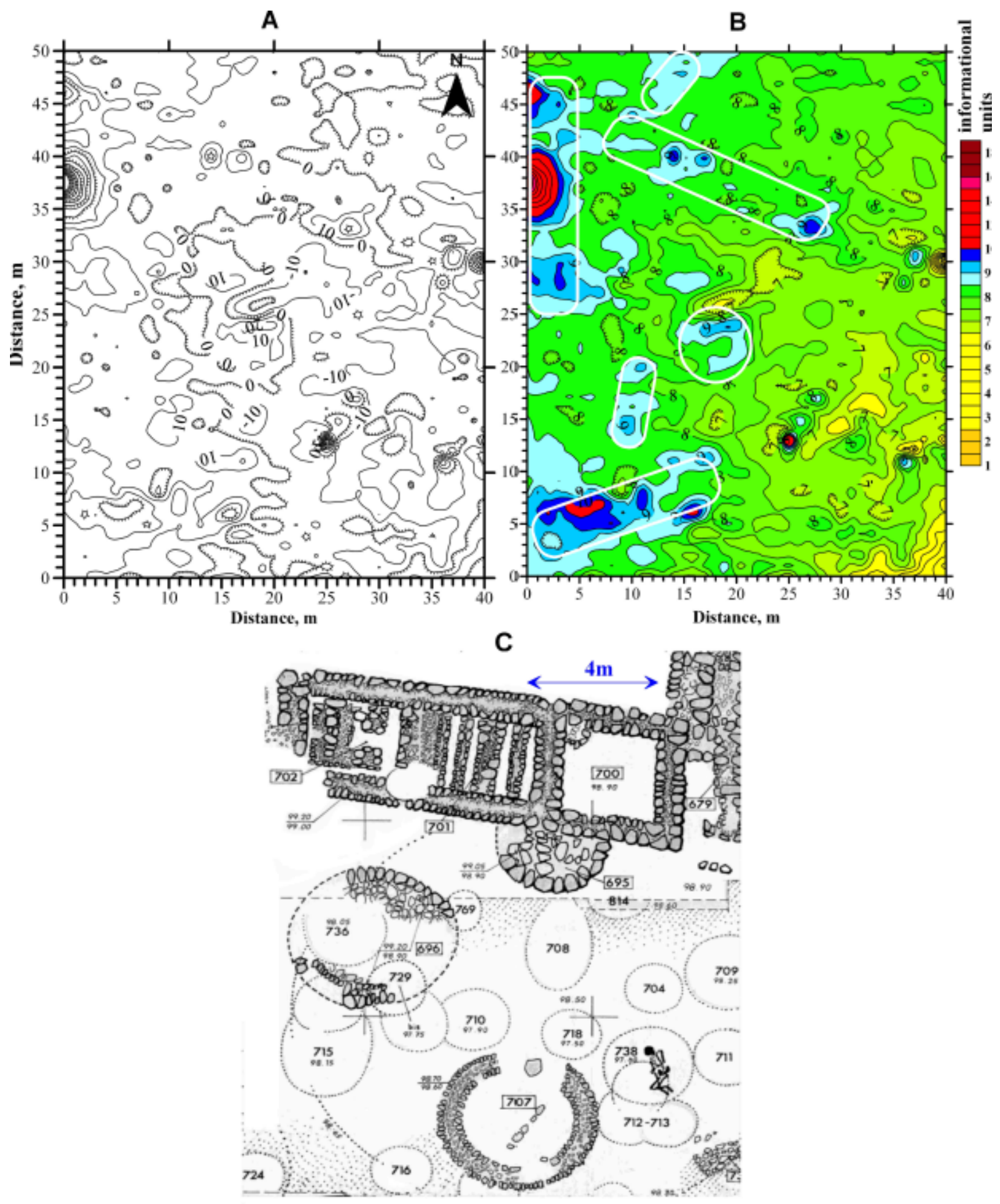

Fig. 8. Magnetic maps of the northern part of Munhata site: (A) observed magnetic map (after Eppelbaum et al., 2000b), (B) magnetic map from (A) transformed to informational parameter, (C) excavated part of the Munhata site, some $10 \mathrm{~m}$ south of the studied site (after Commenge, 1996). 

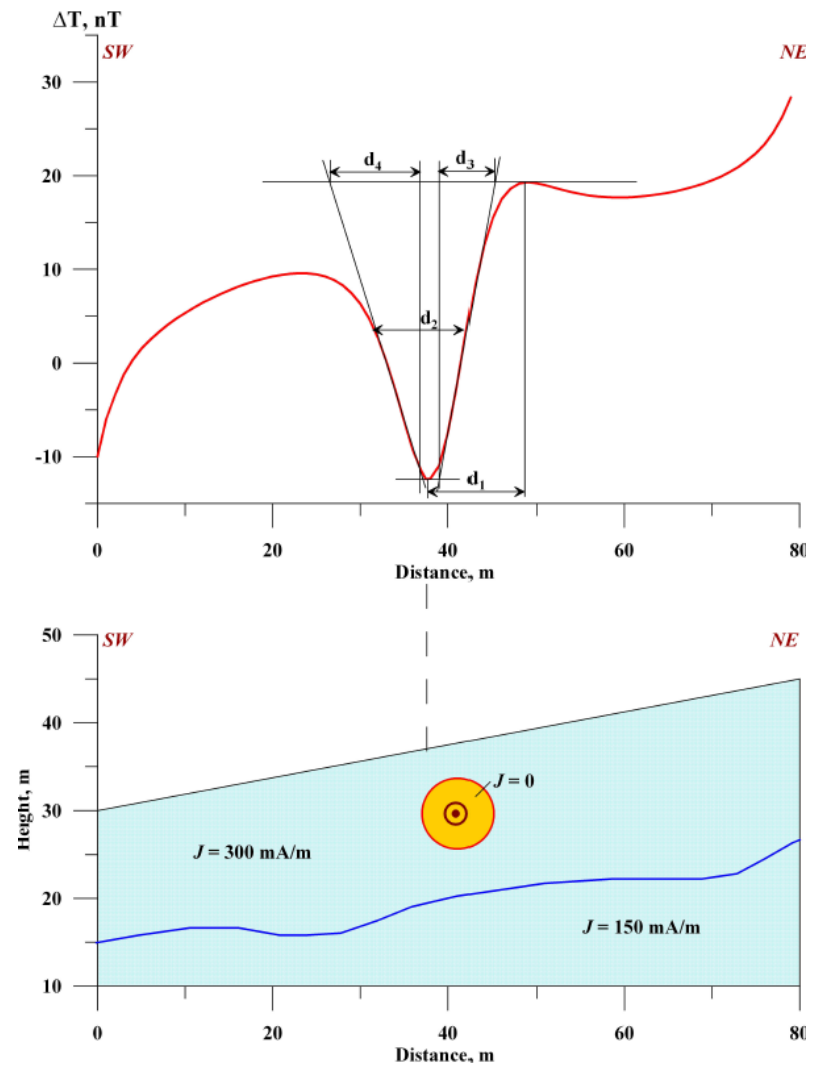

Fig. 9. Model example of magnetic field quantitative analysis under complicated environments. Symbol $\odot$ designates location of the sphere center and arrows show the position of the total magnetic field vector.

Integrating several response functions $\Lambda_{i}$ we can obtain a more accurate and reliable physical-archaeological model of an ancient target.

A simple model presented in Fig. 10 illustrates utilization of two different interpretations of the same ancient remnant by performing a magnetic survey at two different levels $(0.1$ and $3.0 \mathrm{~m}$, respectively). Indeed, from the survey at the $0.1 \mathrm{~m}$ level it is a typical TKB model (Fig. 10a) and at the $3.0 \mathrm{~m}$ level, observations of the anomalous body may be interpreted as an HCC (Fig. 10b). Results of the TKB model interpretation were used to determine a center of the upper edge of the anomalous body (Fig. 10a) and the HCC model for localization of a center of HCC (Fig. 10b). Combining these two models (we have two response functions $\Lambda_{1}$ and $\Lambda_{2}$ from the subdomains $\Omega_{1}$ and $\Omega_{2}$ ), we can develop a common generalized model of the anomalous body (Eppelbaum, 2005).

\subsubsection{Magnetic survey at typical archaeological objects}

The detailed magnetic survey is the most widely used geophysical tool in studying archaeological remains in Israel (e.g., Itkis and Eppelbaum, 1998; Eppelbaum, 2000a;
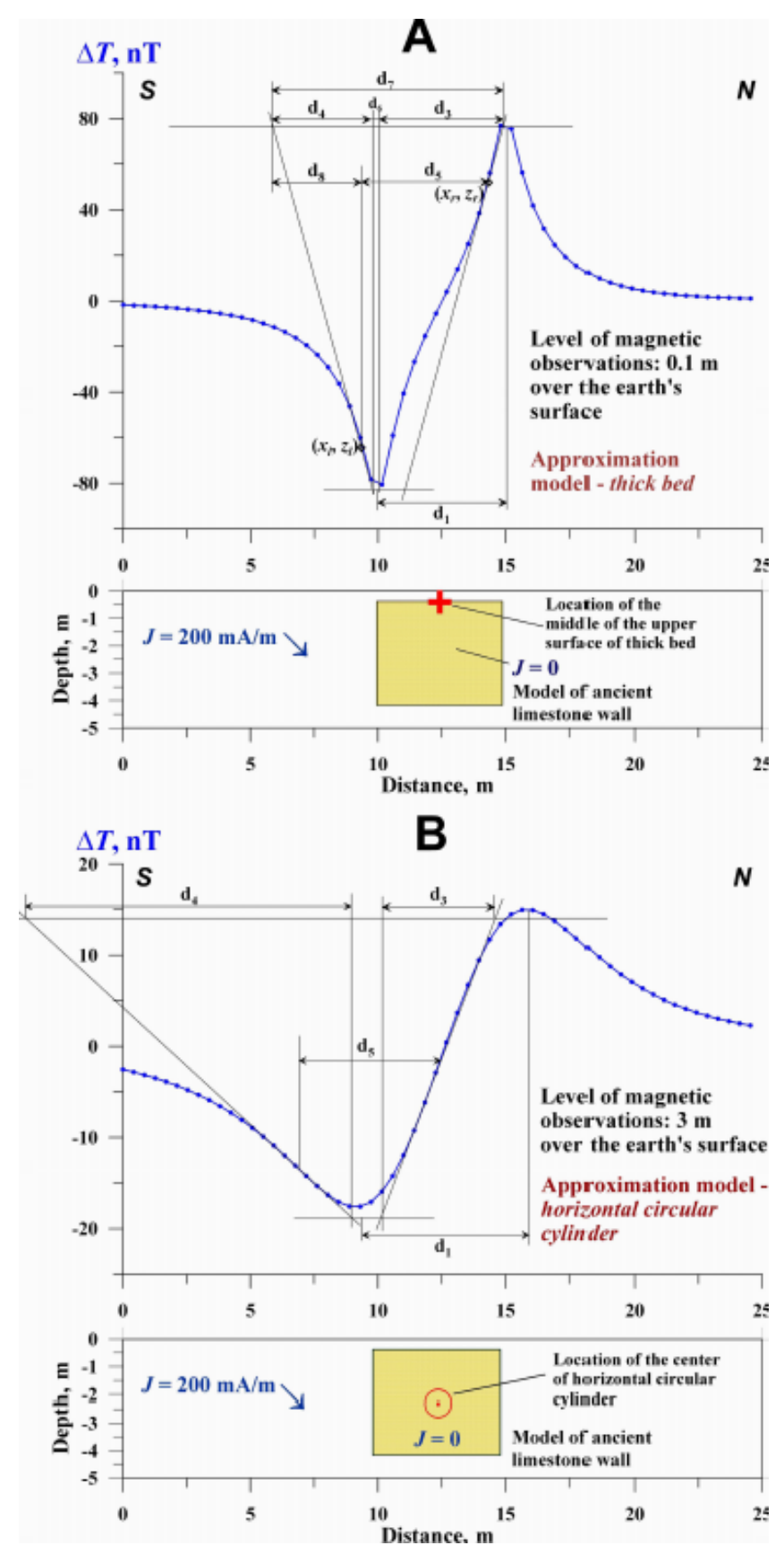

Fig. 10. Realization of two-level observations with two different interpretation models utilized: (A) model of a thick bed, (B) model of the horizontal circular cylinder. Magnetization is denoted as $J$. 
Eppelbaum et al., 2000b, 2001b, 2003a, 2008, 2010a, Eppelbaum and Itkis, 2000, 2003; Itkis et al., 2003). Therefore, conditions of this survey will be considered in detail.

Interpretation of magnetic surveys in Israel is complicated by the strong inclination of the Earth's magnetic field (about $42-46^{\circ}$ ). In addition, the multi-layered and variable structure of the upper part of the geological sequence (Horowitz, 1979; Dan, 1988) presents difficulties in the determination of the level of the normal magnetic field within the sites studied. Sometimes ancient seismological activity found essential reflection in the observed magnetic pattern. Industrial iron and iron-containing objects often produce an intensive noise effect. Uneven terrain relief also disturbs the effect of buried objects and complicates examination of magnetic anomalies. A significant number of the archaeological studied targets are situated in the vicinity of various industrialagricultural objects that also disturb the archaeogeophysical measurements. The complex conditions of the survey require application of sophisticated geophysical equipment and advanced methods of qualitative and quantitative interpretation (Khesin et al., 1996; Eppelbaum et al., 2001b). Detailed magnetic survey was successfully analyzed in the sites of Banias, Beit-Gouvrin, Beit Shemesh, Emmaus, Eynan, Evora, Halutza, Kissufim Road, Megiddo, Munhata, Nahal-Zehora, Nahal Nagit, Sha'ar Ha-Golan, Tel Kara Hadid, Yodefat, etc. (Itkis and Eppelbaum, 1998; Eppelbaum et al., 2003a; Itkis, 2003; Eppelbaum et al., 2006b, 2007; Eppelbaum et al., 2010a, b; Itkis and Eppelbaum, 2009, 2010). Studying of magnetic susceptibility of ancient remains and surrounding media was performed practically at all archaeological sites where magnetic survey was performed (e.g., Itkis and Eppelbaum, 1998; Eppelbaum and Itkis, 2001; Itkis, 2003, 2008).

Some qualitative conclusions about the ancient targets might be obtained from the analysis of low-intensive temporary magnetic variations observed over the targets (Finkelstein and Eppelbaum, 1997). Such examination has an essential importance in the case of impossibility to carry out archaeological excavations. A new laser magnetic field detector permits to observe picoTesla anomalies over ancient targets with a very low magnetic contrast (Finkelstein and Eppelbaum, 1998).

Khesin's methodology for determination of magnetization of the upper part of geological-archaeological section (sequence) by the use of magnetic survey at inclined relief permits to obtain some averaged magnetization without applying numerous kappametric sampling (Eppelbaum et al., 2001b; Khesin and Feinstein, 2005).

The obtained PAMs of different hierarchical complexity (the simplest PAMs reflect recognition of the desired target while complete PAMs represent 3-D models of archaeological remains) are used for substantiation of direct excavations in the recognized areas (as well as for prohibition of industrial activity) and for generating further strategies for archae-
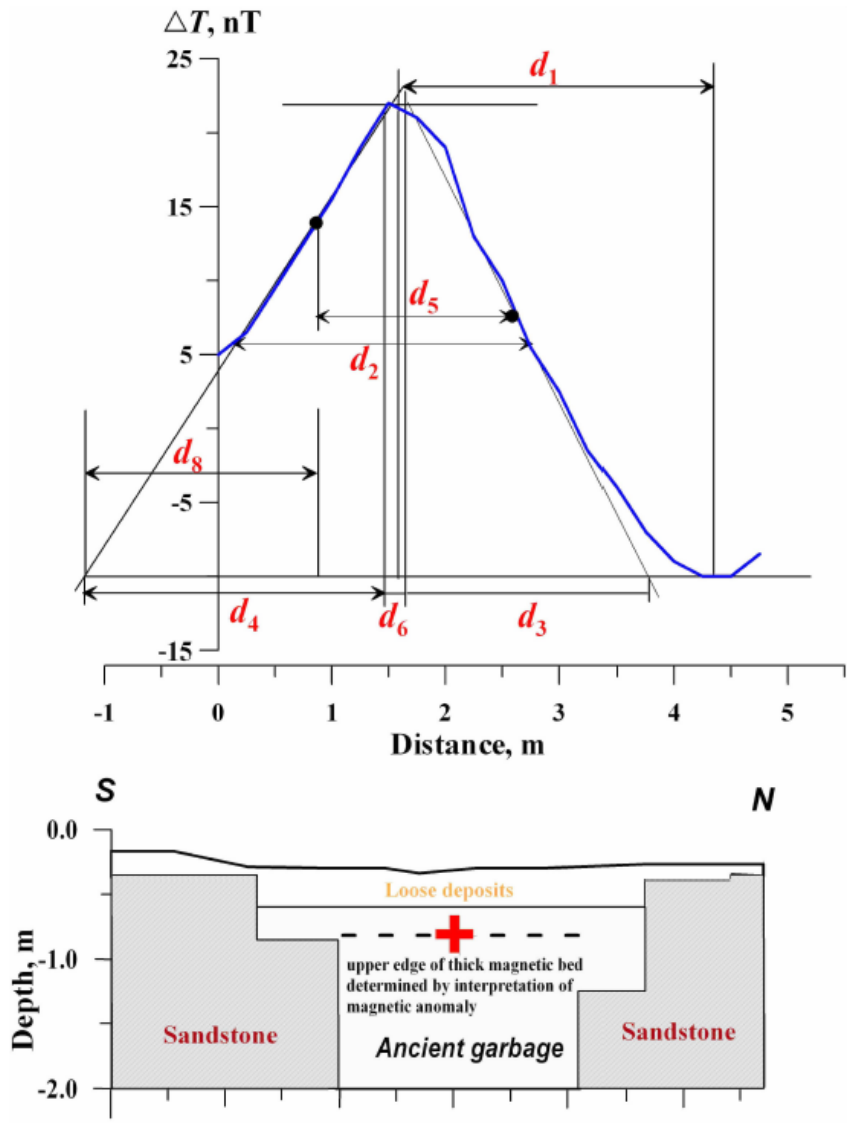

Fig. 11. Interpretation of magnetic anomaly due to ancient garbage at the site of Ashqelon-Marina (Southern Israel) (after Eppelbaum et al., 2000a, with modifications).

ological investigations at sites where ancient remains have been discovered.

Magnetic anomalies analysis at Ashqelon-Marina (Fig. 1) had the aim to examine this area prior to large-scale commercial development. Within this area over 90 pits were identified and most of them were revealed using detailed magnetic prospecting (field works were performed by S. Itkis). The overlying layer of dark brown sandy soil was found to be over $0.5 \mathrm{~m}$ in thickness. The pits were all full of refuse (pottery, flints, bones, and stone vessel fragments, some botanical remains and shells). The most likely purpose of the pits is storage. These features were displayed in the magnetic map as ring (radius of $1.5-2 \mathrm{~m}$ ) positive anomalies (12-20 nT). Figure 11 shows an example of magnetic anomaly interpretation over one such ancient garbage pit (the disturbing body was approximated here by the model of a thick bed) (after Eppelbaum et al., 2000b).

Next example illustrates efficient application of magnetic survey at the ancient metallurgical site of Tel Kara Hadid. This site (Early Islamic period, 7th-11th centuries AD) is located on the western side of the southern Arava Valley, several km north of Eilat in Southern Israel (Fig. 1). The 

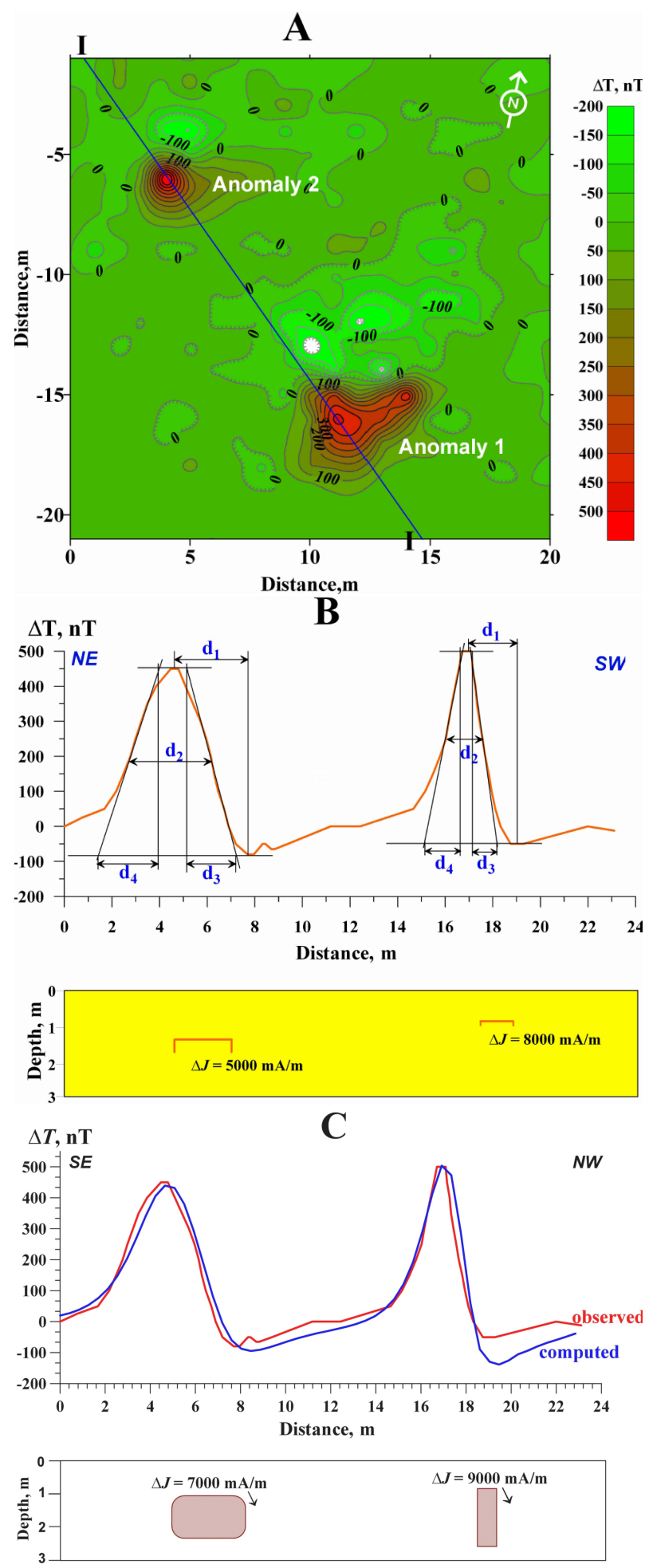

Fig. 12. Solving inverse problem and 3-D modeling of magnetic field in the Tel Kara Hadid site (Southern Israel): (A) Magnetic map of the studied site, (B) Rapid interpretation of magnetic anomalies using developed procedures along the profile I-I. $\Delta J$ denotes the effective magnetization. (C) Results of 3-D modeling. Arrows show the determined position of the total magnetic field vector. site contains to a series of copper mines and smelting camps of that period. The same type of slag, reflecting a uniform technology, characterizes all these smelting sites. On the magnetic map two anomalies are clearly detected (Fig. 12a), which were recognized as furnaces used in ancient metallurgy. Positions of the upper edges of the anomalous bodies (approximation model of a thin bed was used) and their magnetization were determined (Fig. 13b). A 3-D modelling of the magnetic field was applied to develop the final PAM (Fig. 13c) (Eppelbaum et al., 2001b).

\subsection{Self-potential survey}

Apparently, firstly SP measurements at archaeological sites in Israel were performed at the sites of Banias (Paneas), Shaar-Ha-Golan and Halutza (Eppelbaum et al., 2001a, 2004b). Later SP survey was performed at the site of Emmaus-Nikopolis (Eppelbaum et al., 2007), where small SP anomalies were registered over little caves of an artificial origin.

Let us consider combined $\mathrm{SP} /$ magnetic investigations at the site of Halutza. Halutza is located $20 \mathrm{~km}$ southwest of Be'er-Sheva town, in Southern Israel (Fig. 1). It was the central city of southern Palestine in the Roman and Byzantine periods and was occupied from the Nabatean (7th-2nd centuries BC) through the Byzantine period (4th-7th centuries AD). Halutza was founded as a way station for Nabatean traders traveling between Petra (Jordan) and Gaza. Combined geophysical investigations consisting of magnetic and SP measurements were performed in an area of $200 \mathrm{~m}^{2}$ using a $1 \times 1 \mathrm{~m}$ grid (Fig. 13a, b). According to a priori information, limestone structures had been excavated in the area of the site. It was expected that limestone (nonmagnetic) remains occur in the medium with magnetization of $70-100 \mathrm{~mA} / \mathrm{m}$ that could produce the appearance of small negative magnetic anomalies; SP anomaly arising is based on the difference of the electric properties of the target/medium and the generation of the oxidation-reduction processes. The magnetic sensor level was located at $30 \mathrm{~cm}$ above the earth's surface. SP measurements were performed using a microVoltmeter with high input impedance and special non-polarized electrodes ( $\mathrm{Cu}$ in $\mathrm{CuSO}_{4}$ solution) (Eppelbaum et al., 2001a). The potential-array scheme (with a base point electrode) was applied; the depth of electrode grounding was $10-15 \mathrm{~cm}$. Visual analysis of the maps (Fig. 13a, b) indicates that the SP and magnetic fields have different trends, but the recognized negative anomalies in the southern part of this site are placed $2 \mathrm{~m}$ apart. Quantitative interpretation of SP and magnetic anomalies gave similar depths: 90 and $70 \mathrm{~cm}$, respectively. The corresponding PAMs for the performed examination are displayed in Fig. 13c and d (after Eppelbaum et al., 2003b). The ancient walls excavated in direct proximity to the surveyed area occur at a depth of about $80 \mathrm{~cm}$. It allows us to suggest that the similar objects are the sources of anomalies in the area covered by the integrated geophysical survey. 
A

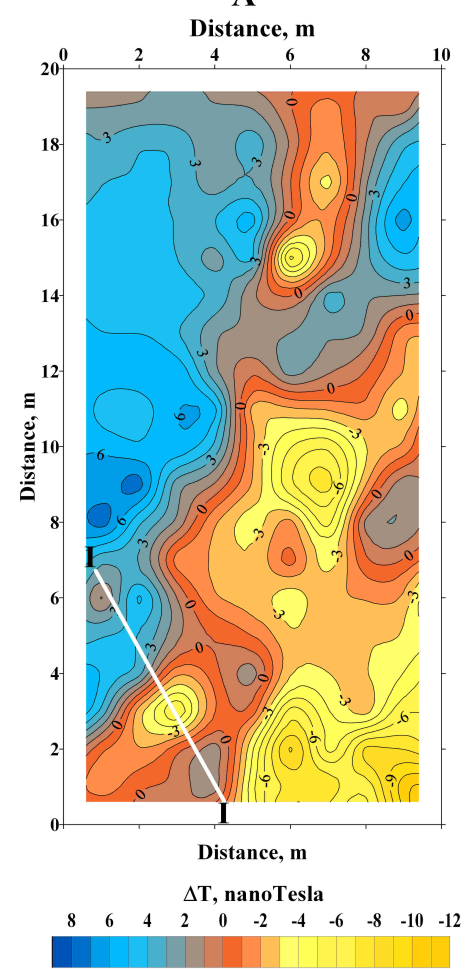

C
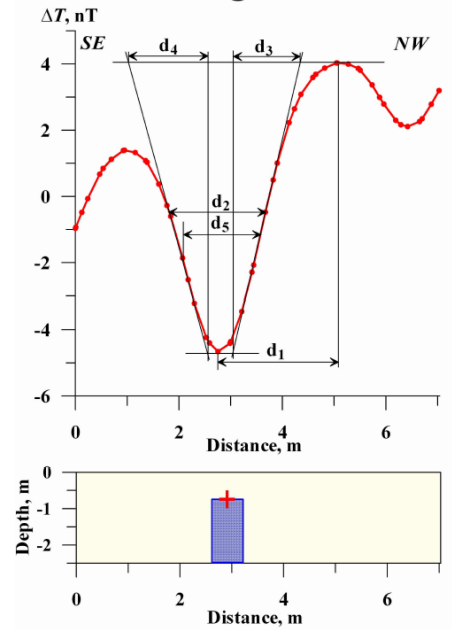

B

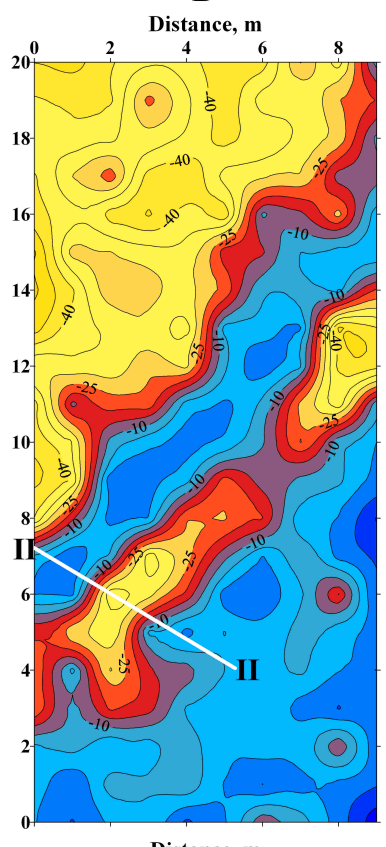

Distance, $\mathbf{m}$

Self-potential field, milliVolt

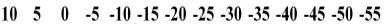

D
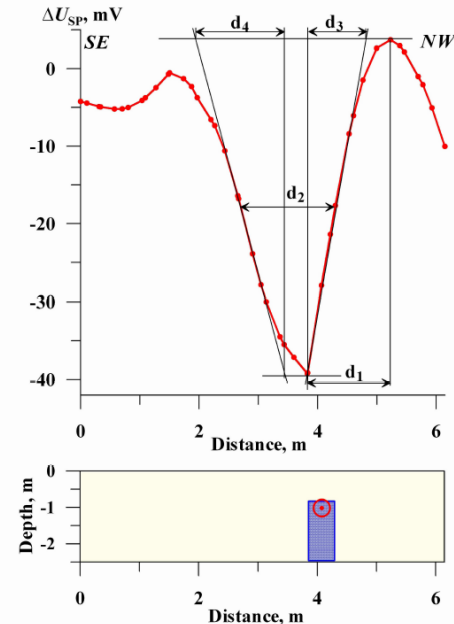

Fig. 13. (A), (B) maps of magnetic (A) and self-potential (B) fields in the Halutza site (Negev desert, Israel) (C), (D). Results of the quantitative interpretation for profile I-I (C) and II-II (D). A cross indicates the position of the middle of upper edge of anomalous body for magnetic anomaly (C), and a small circle is inscribed in the upper edge of anomalous body for the SP anomaly (C).

\subsection{Resistivity survey}

Resistivity (direct current) survey has been applied (by the use of dipole-dipole array) at several archaeological sites at Israeli coastal plane (Tanzi et al., 1983). Resistivity method was applied at the site of Nahal-Tut for identification of remains of Roman fortress in Northern Israel in 1997 (Y. Gurevich and S. Itkis, personal communication, 2008). Electric resistivity tomography (ERT) has been productively explored in Tel Yavne for identifying the thickness of cultural debris, the plan view extent of cultural debris, and the underlying bedrock contact (Bauman, 2005). Nahas et al. (2006) displayed effective application of electrical resistivity tomography at the sites of Yavne, Yavne Yam and Tel Nami on the Israeli Mediterranean coast and Bethsaida at the Sea of Galilee. A Continuous Vertical Electrical Sounding (CVES) 
geoelectric survey in the el-Wad Cave indicated a low resistivity layer at the upper, central part of the cave, suggesting that lithified archeological deposits are preserved at this site (Weinstein-Evron et al., 2003). A test excavation conducted at the site has supported this PAM. On the basis of ERT application at the Cave of Letters (Dead Sea), the Bar Kokhba living surface has been differentiated, and areas of recent rockfall, ancient rockfall and bedrock have been indicated (Reeder et al., 2004). Ginzburg and Levanon (1977) very successfully applied resistivity method in Jerusalem for studying the thickness of the wall of the Mount of the Temple and determination of the underground location of preHerodian city walls in the City of David, as well as at the site of Tel-Afek.

DC mapping of the site of Tel-Afek is the classic example of this method application. The archaeological site of Tel Afek, dating to the Late Bronze Age (1550-1200 BC), is situated about $10 \mathrm{~km}$ east of Tel-Aviv (Fig. 1). One of the main geophysical-archaeological problems at this site consisted in mapping walls of ancient structures, almost completely covered by sediments. Ginzburg and Levanon (1977) previously applied at this site the resisitivity method (altogether 8 profiles were observed) based on the essential differences in geoelectric characteristics between the ancient objects and sediments, and effectively localized several buried wall foundations in the studied area. One of the electric resistivity anomalies was examined (Fig. 14) with applying the advance interpretative methods developed in magnetic prospecting (Eppelbaum, 1999). For developing a PAM, the HCC model was applied. As evident from Fig. 14, the interpretation is in good agreement with the archaeological data.

\subsection{Near-surface temperature survey}

A first attempt to reveal archaeological remains in Israel by the use of near-surface temperature survey was realized by Paparo (1987) at the site of Gamla (Northern Israel). At this site five $80 \mathrm{~m}$ profiles (with $5 \mathrm{~m}$ observation step) and ten $15 \mathrm{~m}$ profiles (with $1 \mathrm{~m}$ observation step) were observed. Substantiation of this examination is thermophysical parameters contrast between the ancient targets (buried basaltic stones) and host medium (limestone underlying the alluvial deposits). The results of examinations were not very successful that obviously was caused by the complex geologicalarchaeological sequence in the Gamla area and insufficient calculation of some disturbing factors.

Near-surface thermal prospecting was applied to delineate qualitatively the remains of a Crusader fortress in the city of Netanya (central Israeli Mediterranean coast) (Paparo, 1991). In this investigation, limestone and kurkar (silicious limestone) ancient remains were reliably identified in the clay and loam surrounding.

A complete methodology of the near-surface temperature investigations at archaeological sites was presented in Eppelbaum (2008b, 2009b).

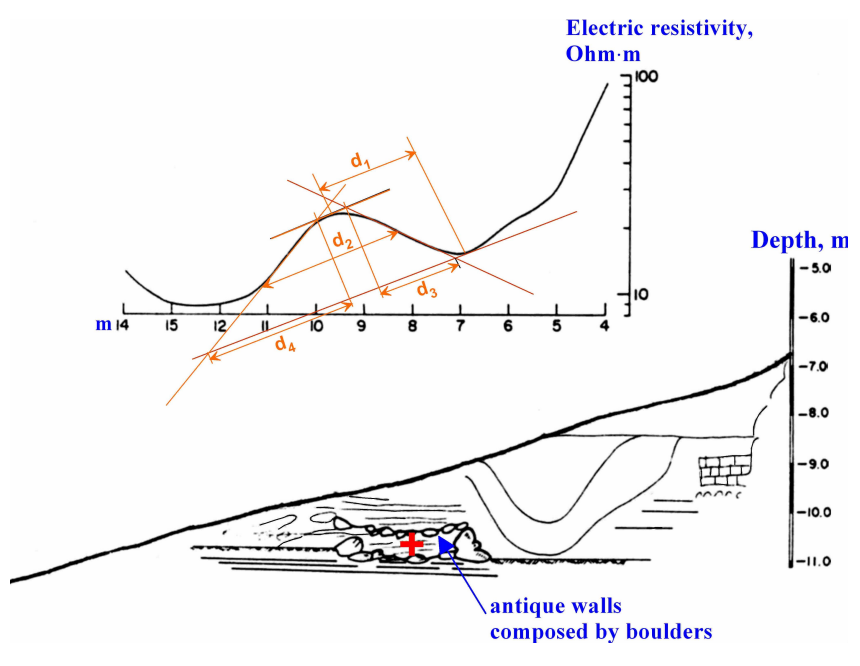

Fig. 14. Inverse problem solution for resistivity anomaly in the archaeological site of Tel Afek, Central Israel (initial data from Ginzburg and Levanon, 1978). A cross in the section designates the location of the center of anomalous body.

\subsection{Gravity field analysis}

Analysis of the numerous archaeological and geological publications as well as the author's investigation (e.g., Eppelbaum, 2000a, b) indicates that the ancient objects supposed for examination by the use of microgravity survey in Israel may be classified (in the decreasing order) by the following way: (1) underground ancient cavities and galleries, (2) walls, remains of temples, churches and various massive constructions, (3) pavements and tombs, (4) Roman aqueducts (under favorable physical-geological environments), (5) areas of ancient primitive metallurgical activity (including furnaces) (under favorable physical-geological environments). Examining the different archaeological targets in Israel, it was supposed that microgravity method might be effectively applied at least on 20-25\% of ancient sites (Eppelbaum, 2009a).

It is necessary to underline that physical measurement of vertical gravity derivatives cannot be replaced by computing of this parameter obtained by any transformation procedures: the second vertical derivative of gravity potential $W_{z z}$ values computed from the field $\Delta g_{B}$, as rule, show decreasing values comparing with the $W_{z z}$ obtained from physical measurements. A simplified model example of buried pavement delineation (pavement excavated at the Megiddo site was utilized as a generalized physical-geological model) is presented in Fig. 15. A buried pavement having the positive density contrast of $400 \mathrm{~kg} / \mathrm{m}^{3}$ and occurring at a depth of $1.8 \mathrm{~m}$ in uniform medium could be easily recognized by microgravity survey (Fig. 15a, anomalous effect from two bodies). Let's will assume a low-density layer $\left(2100 \mathrm{~kg} / \mathrm{m}^{3}\right)$ over the pavement (Fig. 15c). It makes the delineation of the pavement practically impossible in field conditions (registered anomaly 

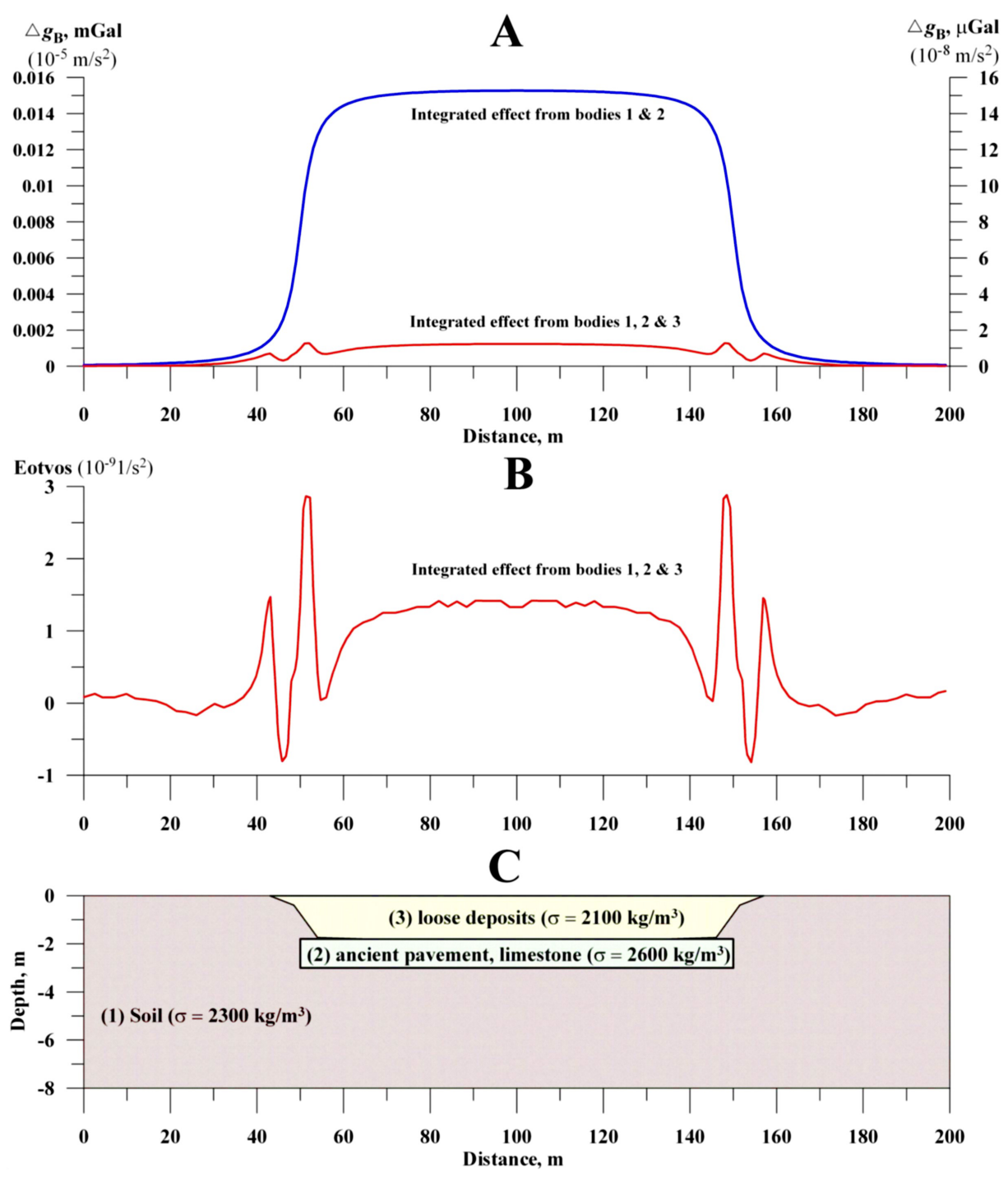

Fig. 15. Comparison of Bouguer gravity and vertical gradient anomalies for a model of buried pavement. (A) Bouguer gravity, (B) vertical gradient $g_{z}\left(W_{z z}\right)$ computed for the base of $1.2 \mathrm{~m},(\mathbf{C})$ archaeological sequence.

is oscillating about 1 microGal) (Fig. 15a, anomalous effect from three bodies). At the same time values of the second vertical derivative of gravity potential $\left(W_{z z}\right)$ (computed for the levels of 0.3 and $1.5 \mathrm{~m}$ ) with a measurable accuracy testify to presence of a disturbing body (Fig. 15b).

\section{Paleomagnetic examination}

Paleomagnetic investigations were effectively applied at many archaeological sites including Abu Matar, Ashqelon, Tel Miqne and Megadim (Sternberg et al., 1999), Bizat Ruhama (Laukhin et al., 2001), Evron Quarry (Ron et al., 2003), Kebara Cave (Sternberg and Lass, 2007), Timna, Yotvata, Mitzpe Evrona, Givat Yocheved, Beer Ora Hill, Tel Kara Hadid (Ben Yosef et al., 2008; Shaar et al., 2010), etc. Borradaile (2003) employed Bayesian statistics for paleomagnetic classification of small samples collected in Israel. Segal et al. (2003) carried out paleomagnetic tests on two archaeological structures as an oven and a limekiln in the Crusader fortress Vadum Iacob (Northern Israel). These fireplaces enable determination of the local direction and intensity of the geomagnetic field on 24 August 1179 , when its construction was terminated by the Arab conquest. Borradaile and Almqvist (2006) analyzed young viscous remagnetization directions at Armageddon (Megiddo), Northern Israel. It is necessary to underline that in many cases paleomagnetic data not only assist to recognize intricate magnetic pattern, but have serious independent significance. 


\section{Near surface seismics}

Apparently, firstly seismic refraction method was applied in Israel to detect a cavity beneath the ancient mosque/synagogue at Machpelah and mapping of foundations of some ancient buildings in the old city of Jerusalem (Dolphin, 1981).

Seismic refraction method was effectively employed at the prehistoric site of el-Wad Cave located on the Mount Carmel in Northern Israel (Weinsten-Evron et al., 1991, 2003). The main aim of this examination was encountering of two distinct lithological layers and measuring the thickness of the upper sediment layer in the various unexcavated segments of the cave. For increasing resolution, spacing between the geophones was set at $0.5 \mathrm{~m}$ and, as a result, this problem was precisely solved (Weinsten-Evron et al., 2003).

Seismic diffraction method was successfully tested at the late prehistoric site of Shiqmim - ancient village in the Be'erSheva river valley in Israel's northern Negev (Witten et al., 1995). The difficulty of this investigation consisted in that the archaeological features occur as much as $7 \mathrm{~m}$ deep in hard-packed soil and are usually completely filled with fine sediment as a result of depositional forces acting over the 6 millennium since their abandonment. The authors note that it is the first attempt to apply diffraction tomography to an archaeological context.

\section{Remote sensing methods}

The airborne thermal video radiometry (ATVR), applied at the Tel Leviah site (Golan Heights, Israel) was capable of detecting small surface temperature variations in relatively high spatial resolution (Ben-Dor et al., 1999). The ATVR images provided additional information about the area that could not be observed from either ground or air by conventional ways.

Experimental microwave remote sensing performed at the Tseelim site (northern Negev desert), and it was indicated that this methodology might be applied for delineation of buried archaeological targets (Daniels et al., 2003).

Infrared and synthetic aperture radar data were used for detection, identification and mapping of ancient drainage system at the sites of Ashalim and Tseelim in the northern Negev (Southern Israel) (Blumberg et al., 2004).

Aerial photography at Tel Yavne (Central Israel) was used for creating base maps, locating land resistivity profiles, identifying surface and near surface archaeological features of interest, and documenting the present conditions of the site (Bauman et al., 2005).

\section{Marine archaeogeophysical investigations}

Mindell and Bingham (2001) have successfully tested high frequency, narrow-beam sub bottom profiler over an 8thcentury BC shipwreck found off the coast of Israel. Weiss et al. (2007) fruitfully employed a system developed for detection and accurate mapping of ferro-metallic objects buried below the seabed in the vicinity of Atlit (northern Mediterranean coast of Israel). This system based on application of precise magnetic gradientometric equipment connected with GPS navigation and mounted at the non-magnetic catamaran (towed by a low-magnetic interfering boat) was carried out at the area of $3.5 \mathrm{~km}^{2}$ on a $0.5 \mathrm{~m}$ grid. A paper of Boyce et al. (2004) suggesting to magnetic marine studying of submerged Roman Harbour (Caesarea Maritima, Israel) is of great interest. The magnetic surveys identified the presence of an extensive hydraulic concrete foundation below the ruined harbour moles. The magnetic anomaly patterns indicate that the concrete foundation was laid out in a header fashion. Magnetic lows within the structure have localized the baffles that were composed by sand to stabilize the concrete foundation walls. A continuation of this investigation (Boyce et al., 2009) has demonstrated that ancient ship ballast (basalts) could be reliably detected and mapped on the seabed using precise magnetic survey.

\section{Other geophysical methods}

\subsection{Piezoelectric imaging}

An experimental piezoelectric studying was performed at the site of Wadi Tahawim

The site, dating to the Early Islamic Period (7-10 centuries BC), is located five kilometers north of the town of Eilat (Fig. 1). The study aimed at locating buried quartz veins that were native sources of gold for ancient metallurgy (Neishtadt et al., 2006). The geological sequence is extremely heterogeneous at the local scale (varying from boulders to silt), and covers the quartz veins complicating their identification. Taking into account that piezoelectric investigations are the best methods for delineation of quartz veins, several experimental profiles were made using a MORION-2001 instrument (Neishtadt et al., 2006). Measurements (both electrode spacings and shotpoint distances were $5 \mathrm{~m}$ ) conducted over a quartz vein covered by surface sediments (approximately of $0.4 \mathrm{~m}$ thickness) produced a sharp (500 microVolt) piezoelectric anomaly (Fig. 16). Piezoelectric values recorded over the host rocks (clays and pebbles) were close to zero. It should be noted that the methods developed in magnetic prospecting for a thick bed interpretation model were successfully applied for examination of this anomaly.

\subsection{Vertical electric sounding}

Weinstein-Evron et al. (2003) have applied the vertical electric sounding (VES) to delineate prehistoric caves in Mount Carmel (Israeli coastal plane, Northern Israel). Ezersky et al. (2000) have been mapped by the use of VES the stalagmite-rich Soreq Cave in Central Israel. 


\subsection{Very low frequency method}

Eppelbaum and Khesin (1995) proposed a new scheme for VLF data interpretation and proved the feasibility of applying it in Israel for solving various environmental and archaeological problems. Geophysicists of the Isotope Environmental Company (Gedera, Israel) have successfully employed VLF survey for delineation of several archaeological sites in Israel (personal communication with Isotope workers, 1999).

\subsection{Frequency domain electromagnetic method}

Frequency Domain Electromagnetic method (FDEM) was applied in Soreq Cave (Ezersky et al., 2000) where fairly strong resistivity anomaly (more than $800 \mathrm{ohm} \cdot \mathrm{m}$ as compared to approximately $200-400 \mathrm{ohm} \cdot \mathrm{m}$ of background resistivities) was detected above the known cave (when measurements were carried out with $20 \mathrm{~m}$ offset). FDEM measurements were used mainly to locate resistivity anomalies in the lateral directions.

\subsection{Ancient climate examination}

Results of Ezersky et al. (2000) VES analyses in Soreq Cave were utilized for the paleoclimate data reconstruction from speleothemes. Eppelbaum et al. (2006c) assessed the possibility of archaeo-temperatures determination by the measurements of modern temperature values observed in shallow boreholes. It should be noted that obtained values of ancient temperatures would help estimate the present physicalchemical conditions of materials utilized for building of antique constructions.

\subsection{Dating of archaeological targets}

A radiocarbon dating at site of Tel-Rehov (Central Israel) was utilized for modification of the traditional chronology of the Iron Age in the Levant (Bruins et al., 2003). Ageestimates ranging from 50 to $70 \mathrm{ky}$ were obtained for the Mousterian deposits of Amud Cave (Northern Israel) from thermoluminescence measurements performed on 19 burnt flints (Valladas et al., 1999). At the same cave an electron spin resonance (ESR) was applied for dating of Middle Paleolithic layers (Rink et al., 2001). For the aim of age determination of archaeological target appearing at the day surface (Holon town, Central Israel) a thermoluminescence method has been employed (Porat et al., 1999). Boaretto et al. (2000) have employed ${ }^{10} \mathrm{Be}$ and ${ }^{26} \mathrm{Al}$ in quartz for dating the prehistoric sediments in Tabun Cave (Mt Carmel, Northern Israel). Verri et al. (2004) have performed investigation of ${ }^{10} \mathrm{Be}$ concentration to manufacture flint artifacts 300000 years old from Qesem Cave (Central Israel). Other successful application of this method was illustrated by Goldfrey-Smith et al. (2003) at the Kebaran site of Nahal Hadera V (NHV) in the coastal plain of Israel. McDermott et al. (2003) demon-
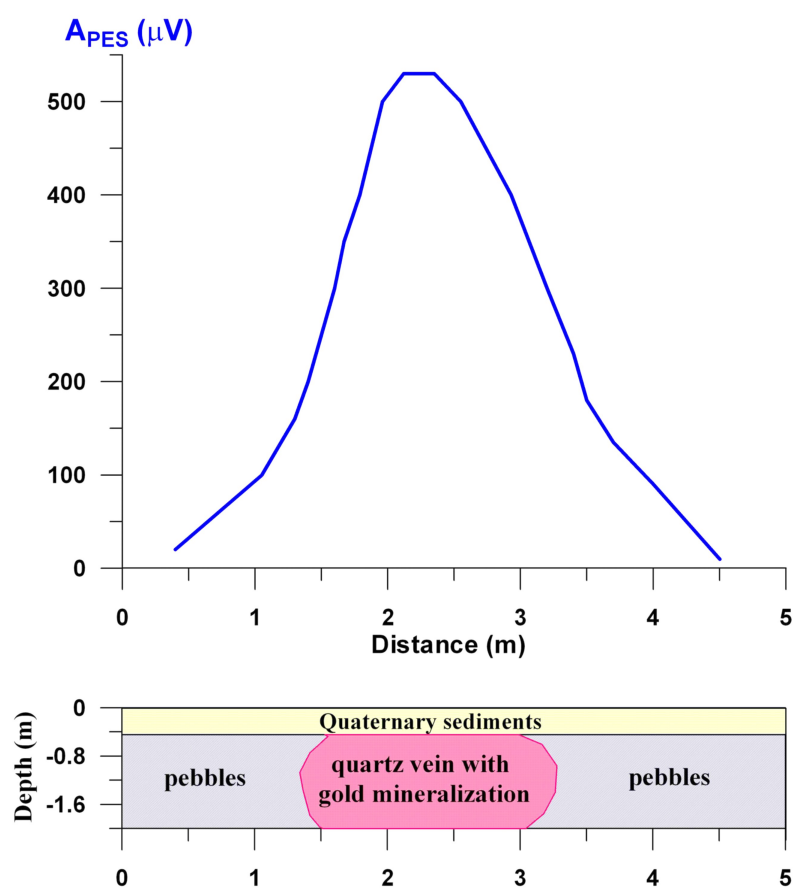

Fig. 16. Piezoelectric anomaly over an ancient gold-bearing mine, Southern Israel (after Neishtadt et al., 2006).

strated combining application of ESR and uranium-series dating at several Israeli archaeological sites. Radiometric dating of the Siloam tunnel in Jerusalem (Frumkin et al., 2003) permitted to determine exactly its time of construction (about 700 BC). A new dating method based on the Meissner response in the superconducting state was tested in site of Tel-Dor (Caesarea, Israel costal plain) (Reich et al., 2003).

\subsection{Fourier-transform infrared spectrometry}

A portative Fourier-transform infrared spectrometry was successfully used in the Kebara cave (Northern Israel) for differentiation of underlying rocks by their physical-chemical characteristics (Weiner et al., 1993).

\section{Integrated geophysical surveys at archaeological sites in Israel}

\subsection{Estimation of geophysical integration efficiency on the basis of Kotelnikov's criterion}

The complex and multi-layered structure of many archaeological sites and their remains, and known ambiguity of interpretation of results from single geophysical methods, calls for an integration of different geophysical methods (Khesin et al., 1996; Eppelbaum et al., 2006a). The necessity of close integration between archaeology, geophysics and chemistry is clearly illustrated by Pollard and Bray (2007). 
A simple calculation of integration preferences is conducted in Khesin and Eppelbaum (1997). If a set of methods is focused on investigating some independent indicators of equal value, the anomaly detection reliability $\gamma$ can be described by an error function (probability integral) as

$\gamma=\operatorname{erf}\left(1 / 2 \sqrt{\sum_{i} v_{i}}\right)$

where $v_{i}$ is the ratio of the anomaly square to the noise dispersion for each $i$ th geophysical field.

Now let us assume that the anomaly is indicated by three points and that the mean square of the anomaly for each field is equal to noise dispersion. For a single method, the reliability of detection of an anomaly of a known form and intensity by Kotelnikov's criterion is expressed by erf $\left(v_{i} / 2\right)$. Then, the value of reliability for individual methods is 0.61 and those of a set of two and three methods is 0.77 and 0.87 , respectively (according to Eq. 6). Risk of an erroneous solution ( $q$ value) is calculated as $q=1-\gamma$.

This means that the risk of an erroneous solution at the integration of two or three methods decreases by the factors of 1.7 and 3 , respectively. A comparison of the risk with the expenditures enables an optimum set of methods to be determined.

\subsection{Cartographic problem of "four colors" as substantiation of geophysical methods integration}

The intuitive use of a small number of integration elements in practice can be theoretically substantiated using the solution of a well-known mathematical and cartographic problem of "four colors" (Appel and Haken, 1989) for geophysical methods integration (Khesin and Eppelbaum, 1997).

For the simplicity, it will be assumed that the goal of each archaeogeophysical prospecting stage is the selection of an area for more detailed operations at the next stage. The result of prospecting will be used for primarily evaluation of the areas under investigation and their classification into two groups: those worthy and unworthy of further studying. The objective of prospecting is to obtain maximum information at given expenditures (see Sect. 2).

Let us now examine the "four colors theorem" from this standpoint. Using elementary notions of the theory of graphs, the problem can be formulated as follows: one has to prove that all vertices of an arbitrary planar graph can be colored with four colors in such a way that no two vertices joined by a common edge are of the same color. It was proved as early as the middle of the 19th century that four colors suffice to color different counties on the map of England. A general solution of this theorem was obtained by Appel and Haken (1989) and finally updated by Thomas (1998).

Any area under study can be divided into separate geological zones according to certain indicators. The following system of classification according to their prospects has been
Table 1. Subdivision of an archaeological according to results of geophysical surveys.

\begin{tabular}{|c|c|c|}
\hline $\begin{array}{l}\text { Level of knowledge } \\
\text { of the area }\end{array}$ & $\begin{array}{l}\text { Geophysical method } \\
\text { first second }\end{array}$ & $\begin{array}{l}\text { Combination } \\
\text { (color) number }\end{array}$ \\
\hline $\operatorname{High}(\mathrm{H})$ & + & 1 \\
\hline Medium (M) & + & 2 \\
\hline Low (L) & - & 3 \\
\hline Unknown (U) & no necessary data & 4 \\
\hline
\end{tabular}

adopted in the USA (Suggestions, 1978): high (H), medium (M), low (L) and unknown (U). The objective of prediction is to single out promising areas (if any) from the whole set by means of an integrated geophysical survey. By colors we mean various combinations of geophysical methods. A positive conclusion made by the data of a certain prospecting method will be labeled as (+), and a negative conclusion as (-). It is evident that a combination of at least two independent geophysical methods is necessary for the first three gradations ( $\mathrm{H}, \mathrm{M}$ and $\mathrm{L}$ ); the gradation $\mathrm{U}$ implies no application of the method set (on the necessary scale or not at all) on the area under investigation (Table 1).

The geophysical methods employed are a priori assumed as being of equal significance. The threshold field values (the borderline between plus and minus) and particular types of geophysical investigations are determined according to prospecting results for similar objects investigated previously and other geological and geophysical considerations. By area borderline we mean a certain line (surface), where specified physical characteristics pass over a threshold field values. These physical characteristics may, for example, include values of observed fields, field gradients or indicators of field variability.

\subsection{Integrated archaeogeophysical surveys in Israel}

The known combined archaeogeophysical investigations in Israel (unfortunately, at least $50 \%$ of the performed surveys exist only as non-published reports) are compiled in Table 2.

Certainly, the aforementioned applied geophysical method combinations should be qualitatively and quantitatively estimated, but it is a matter of separate investigation.

\section{Development of multi-dimensional physical- archaeological database}

The constant increase in geophysical-archaeological data and their revision has necessitated the development of an Integrated Archaeological-Geophysical Data Base (IAGDB). Obviously, it must be multi-componential and dynamic in character (Eppelbaum and Ben-Avraham, 2002). Besides spatial topographic coordinates $(x, y, z)$ of archaeological sites, the IAGDB should include all values of the geophysical 
Table 2. Integrated geophysical investigations at archaeological sites in Israel.

\begin{tabular}{|c|c|c|c|c|}
\hline Geophysical surveys & $\begin{array}{l}\text { Archaeological } \\
\text { site }\end{array}$ & Location of site & Desired targets & Authors \\
\hline Seismics and GPR & Old City & Jerusalem & $\begin{array}{l}\text { buried ancient } \\
\text { constructions }\end{array}$ & Dolphin, 1981 \\
\hline Seismics and GPR & El-Wad Cave & Mt. Carmel & underground caves & $\begin{array}{l}\text { Beck and Weinstein- } \\
\text { Evron, } 1997\end{array}$ \\
\hline CVES and FDEM & Soreq Cave & $\begin{array}{l}\text { Judean Hills, } \\
\text { Central Israel }\end{array}$ & cave boundaries & Ezersky et al., 2000 \\
\hline Magnetic and SP & Banias & Northern Israel & $\begin{array}{l}\text { buried Roman } \\
\text { cemetery and } \\
\text { aqueduct }\end{array}$ & $\begin{array}{l}\text { Eppelbaum et al., 2001a; } \\
\text { Itkis and Eppelbaum, } 2009\end{array}$ \\
\hline Magnetic and SP & Halutza & Southern Israel & $\begin{array}{l}\text { hidden Roman } \\
\text { building remains }\end{array}$ & Eppelbaum et al., 2003a \\
\hline $\begin{array}{l}\text { GPR, seismics and } \\
\text { CVES }\end{array}$ & El-Wad Cave & Mt. Carmel & underground caves & Weinstein-Evron et al., 2003 \\
\hline $\begin{array}{l}\text { GPR, infrared survey } \\
\text { and synthetic aperture } \\
\text { radar }\end{array}$ & $\begin{array}{l}\text { Ashalim and } \\
\text { Tseelim }\end{array}$ & $\begin{array}{l}\text { northern part of } \\
\text { Negev desert }\end{array}$ & $\begin{array}{l}\text { ancient buried } \\
\text { drainage systems }\end{array}$ & Blumberg et al., 2004 \\
\hline GPR and ERT & Cave of Letters & Dead Sea region & living surfaces & Reeder et al., 2004 \\
\hline $\begin{array}{l}\text { ERT and aerial } \\
\text { photography }\end{array}$ & Tel Yavne & $\begin{array}{l}\text { central Israeli } \\
\text { coastal plain }\end{array}$ & $\begin{array}{l}\text { thickness of cultural } \\
\text { debris and ancient } \\
\text { constructions }\end{array}$ & Bauman et al., 2005 \\
\hline $\begin{array}{l}\text { Magnetic gradiometry } \\
\text { and EM } 38 \text { terrain } \\
\text { conductivity }\end{array}$ & Tel Nami & $\begin{array}{l}\text { northern Israeli } \\
\text { coastal plain }\end{array}$ & $\begin{array}{l}\text { ancient cultural } \\
\text { remains }\end{array}$ & Nahas et al., 2006 \\
\hline $\begin{array}{l}\text { Magnetic and } \\
\text { resistivity }\end{array}$ & Nahal-Tut & Northern Israel & $\begin{array}{l}\text { remains of Roman } \\
\text { fortress }\end{array}$ & $\begin{array}{l}\text { Itkis and Gurveich, } \\
\text { personal communication, } \\
2008\end{array}$ \\
\hline
\end{tabular}

fields (s) observations over or under the earth's surface, results of the repeated measurements of the geophysical fields (s) repeated measurements over different periods of time, as well as during archaeological excavations. It is also necessary to digitize the geophysical survey results of previous years and to distinguish their relation to other databases (geological, geochemical, paeleostructural, paleosedimentation, paleobotanical, paleobiogeographical, etc.) (Eppelbaum et al., 2010b).

As a basis for the IAGDB development one could use Access DB (obviously, with utilization of all necessary graphic archaeological-geological data sets). Development of such a constantly growing database will increase effectiveness of geophysical examination of archaeological targets by simplifying and speeding up the planning, implementation and analysis of archaeogeophysical investigations. From a regional point of view, the Israeli IAGDB could be connected with similar databases from neighboring countries in the Mediterranean, the Near and Middle East (Eppelbaum et al., 2010b). The next step, apparently, will include a creation of Virtual Archaeology models (Pelfer et al., 2004; Jeffery, 2007) on the basis of combined simultaneous analysis of all possible geophysical, physical, chemical, environmental and other indicators.

\section{Future perspectives: remote operative vehicle multilevel survey}

Among the natural stationary disturbances compiled in Fig. 3 is presented such factors as swampy soil, dense vegetation, loose ground and uneven terrain relief. These factors often complicate performing land archaeogeophysical survey. The new Remote Operated Vehicles (ROV) generation - small and maneuvering vehicles - can fly at levels of few (and even one) meters over the earth's surface (flowing the relief forms) and carry out combined geophysical measurements. The ROV geophysical investigations may be performed during short time period and will have a low exploitation cost. 
Measurements of geophysical fields at different observation levels could provide new unique archaeological-geophysical information (it follows, for instance, from analysis of Fig. 10; besides this, the most effective application of characteristic point method for inverse problem solution (Khesin et al., 1996) demands knowledge of geophysical field behavior at two levels). Khesin's methodology for determination of magnetization of the upper part of geological section (Eppelbaum et al., 2001b; Khesin and Feinstein, 2005) might be applied for the different levels of ROV observation: as a result the obtained magnetization values will reflect the different depth intervals. Finally, multilevel areal observations might be utilized for the procedure of downward continuation on the basis of Gauss' theorem (Eppelbaum et al., 2008). The ROV archaeogeophysical surveys at the areas of world recognized religious and cultural artifacts (where excavations practically always are suppressed and surface survey is hampered) might have a great importance (Eppelbaum, 2010).

It is proposed that the most prospective geophysical integration for ROV should include measurements of magnetic and VLF electromagnetic fields (Eppelbaum et al., 2000a; Eppelbaum, 2008a). GPS (with utilization of the improved wide-band Kalman filtering (Eppelbaum, 2008a)) will assure an exact topogeodetic relation for the proposed observations. Integration of land and ROV geophysical data will provide a distinctive success in the archeological sites examination (Eppelbaum, 2008a). Taking into account the current progress with underwater geophysical imaging (e.g., Rigaud, 2007), similar integration may be realized (for marine and underwater geophysical examinations) at numerous archaeological sites located in the littoral zones of Israeli marine areas.

\section{Conclusions}

Many thousands of archaeological sites occur in complex geological media in Israel. Their localization and classification may be realized by different ways, but information characteristics will help to estimate the concrete method effectiveness. The various kinds of noise arising in archaeogeophysical studying are briefly described and arranged. It concluded that the GPR and magnetic survey at present are the most employed and efficient geophysical methods at archaeological sites in Israel. At the same time, a variety of other geophysical (physical) methods were successfully applied at Israeli archaeological sites, including marine and remote sensing studying. The final aim of different processing methods, application of algorithms and interpretations, is creation of the Physical-Archaeological Models (PAMs) of the ancient buried remains. PAMs of different types may be used to undertake excavations in recognized areas and for planning upcoming archaeological investigations at sites where ancient remains have been discovered. Development of the multidimensional dynamic physical-archaeological database will help effectively join different branches of archaeological and related sciences. Obviously, the wide application of low cost and operative ROV for carrying out geophysical multilevel survey will increase the effectiveness of geophysical methods application at the recent future.

Acknowledgements. The author is grateful to two anonymous reviewers, whose critical comments and valuable suggestions were helpful in final preparing this paper.

Edited by: L. Eppelbaum, N. Masini, and F. Soldovieri Reviewed by: two anonymous referees

\section{References}

Appel, K. and Haken, W.: Every Planar Map Is Four Colorable, Contemporary Mathematics, Providence (R.I.), Amer. Math Soc., 98, 741 pp., 1989.

Bashirov, A. E., Eppelbaum, L. V., and Mishne, L. R.: Improving Eötvös corrections by wide-band noise Kalman filtering, Geophys. J. Int., 108(1), 193-197, 1992.

Batey, R. A.: Subsurface Interface Radar at Sepphoris, Israel 1985, J. Field Archaeol., 14(1), 1-8, 1987.

Bauman, P., Parker, D., Coren, A., Freund, R., and Reeder, P.: Archaeological Reconnaissance at Tel Yavne, Israel: 2-D Electrical Imaging and Low Altitude Aerial Photography, CSEG Recorder, No. 6, 28-33, 2005.

Ben-Dor, E., Portugali, J., Kochavi, M., Shimoni, M., and Vinitzky, L.: Airborne thermal video radiometry and excavation planning at Tel Leviah, Golan Heights, Israel, J. Field Archaeol., 26(2), 117-127, 1999.

Ben-Menahem, A.: Earthquake catalogue for the Middle East (92 BC-1980 AD), B. Geofis. Teor Appl., 21(84), 245-310, 1979.

Ben-Yosef, E., Tauxe, L., Ron, H., Agnon, A., Avner, U., Najjar, M., and Levy, T. E.: A new approach for geomagnetic archaeointensity research: insights on ancient metallurgy in the Southern Levant, J. Archaeol. Sci., 25, 2863-2879, 2008.

Bentley, J. and Schneider, T. J.: Statistics and Archaeology in Israel, Comput. Stat. Data An., 32, 465-483, 2000.

Berkovitch, A. L. and Eppelbaum, L. V.: From seismic inversion to applied optics: A novel approach to design of complex systems, Scientific Israel, 2, 12-26, 2009.

Berkovitch, A. L., Eppelbaum, L. V., and Basson, U.: Application of multifocusing seismic processing to the GPR data analysis, Selected Papers presented at the Ann. SAGEEP Confer., Hyatt Regency Crystal City, Arlington, USA, 597-606, 2000.

Boaretto, E., Berkovits, D., Hass, M., Hui, S.K., Kaufman, A., Paul, M., and Weinerm S.: Dating of prehistoric caves sediments and flints using ${ }^{10} \mathrm{Be}$ and ${ }^{26} \mathrm{Al}$ in quartz from Tabun Cave (Israel): Progress report, Nuclear Instruments and Methods in Physics Research, B172, 767-771, 2000.

Borradaile, G. J.: Viscous magnetization, archaeology and Bayesian statistics of small samples from Israel and England, Geophys. Res. Lett., 30(10), 1528, doi:10.1029/2003GL016977, 2003.

Borradaile, G. J. and Almqvist, B. S.: Installation age of limestone masonry determined from its viscous remagnetization, Geoarchaeology, 21(1), 29-60, 2006. 
Boyce, J. I., Reinhardt, E. G., Raban, A., and Pozza, M. R.: The utility of marine magnetic surveying for mapping buried hydraulic concrete harbour structures: Marine magnetic survey of a submerged roman harbour, Caesarea Maritima, Israel, The International Journal of Nautical Archaeology, 33(1), 122-136, 2004.

Boyce, J. I., Reinhardt, E. G., and Goodman, B. M.: Magnetic detection of ship ballast deposits and anchorage sites in King Herod's Roman harbour, Caesarea Maritima, Israel, J. Archaeol. Sci., 36, 1516-1526, 2009.

Blumberg, D. G., Neta, T., Margalit, N., Lazar, M., and Freilikher, V.: Mapping exposed and buried drainage systems using remote sensing in the Negev Desert, Israel, Geomorphology, 61, 239250, 2004

Bruins, H. J., van der Plicht, J., and Mazar, A.: ${ }^{14} \mathrm{C}$ dates from Tel-Rehov: Iron-age chronology, Pharaohs and Hebrew kings, Science, 300, 315-318, 2003.

Commenge, C.: Horvat Minha (el-Munhata), Excavations and Survey in Israel, 15, 43 p., 1996.

Dan, J.: The soils of the land of Israel, in: The Zoogeography of Israel, edited by: Yom-Tov, Y. and Tchernov, E., W. Junk Publishers, Dordrecht, The Netherlands, 95-128, 1988.

Daniels, J., Blumberg, D. J., Vulfson, L. D., Kotlyar, A. L., Freiliker, V., Ronen, G., and Ben-Asher J.: Microwave remote sensing of physically buried objects in the Negev Desert: implications for environmental research, Remote Sens. Environ., 86, 243-256, 2003.

Dolphin, L. T.: Geophysical methods for archaeological surveys in Israel, Stanford Research International, Menlo Park, Calif., 7 pp., 1981.

Ellenblum, R., Marco, S., Agnon, A., Rockwell, T., and Boas, A.: Crusader castle torn apart by earthquake at dawn, 20 May 1202, Geology, 26(4), 303-306, 1998.

Eppelbaum, L. V.: The development of methods for processing and interpretation of natural geophysical fields in prospecting for pyrite ores under mountainous conditions, Ph.D Thesis, Inst. of Geophysics, Georgian Academy of Sciences, Tbilisi, Georgia, 1989.

Eppelbaum, L. V.: Quantitative interpretation of resistivity anomalies using advanced methods developed in magnetic prospecting, Trans. of the XXIV General Assembly of the Europ. Geoph. Soc., Strasburg, 1(1), 166 pp., 1999.

Eppelbaum, L. V.: Detailed geophysical investigations at archaeological sites, in: Relation between archaeology and other scientific disciplines, edited by: Nissenbaum, A., Collection of Papers, Weitzman Inst., Rehovot, Israel, 8, 39-54, 2000a (in Hebrew).

Eppelbaum, L. V.: Applicability of geophysical methods for localization of archaeological targets: An introduction, Geoinformatics, 11(1), 19-28, 2000b.

Eppelbaum, L. V.: Multilevel observations of magnetic field at archaeological sites as additional interpreting tool, Proceed. of the 6th Conference of Archaeological Prospection, Roma, Italy, 4 pp., 2005.

Eppelbaum, L.V.: Introduction to Potential Geophysical Fields, Handmanual for students, Tel Aviv University, 214 pp., 2007.

Eppelbaum, L. V.: Remote operated vehicle geophysical survey using magnetic and VLF methods: proposed schemes for data processing and interpretation, Proceed. of the Symp. on the Application of Geophysics to Engineering and Environmental Problems,
Philadelphia, USA, 938-963, 2008a.

Eppelbaum, L. V.: On the application of near-surface temperature investigations for delineation of archaeological targets, Trans. of the 1st International Workshop on Advances in Remote Sensing for Archaeology and Cultural Heritage Management, Rome, Italy, 179-183, 2008b.

Eppelbaum, L. V.: Application of microgravity at archaeological sites in Israel: Some estimation derived from 3D modeling and quantitative analysis of gravity field, Proceed. of the 22nd SAGEEP Conference, 22(1), 434-446, 2009a.

Eppelbaum, L. V.: Near-surface temperature survey: An independent tool for buried archaeological targets delineation, J. Cult. Herit., 12, Suppl.1, e93-e103, 2009b.

Eppelbaum, L. V.: Methodology of detailed geophysical examination of the areas of world recognized religious and cultural artifacts, Trans. of the 6th EUG Meet., Geophysical Research Abstracts, 12, EGU2010-5859, Vienna, Austria, 3 pp., 2010.

Eppelbaum, L. and Ben-Avraham, Z.: On the development of 4D geophysical Data Base of archaeological sites in Israel, Trans. of the Conf. of the Israel Geol. Soc. Ann. Meet., MaHagan - Lake Kinneret, Israel, p. 21, 2002.

Eppelbaum, L., Ben-Avraham, Z., Itkis, S., and Kouznetsov, S.: First results of self-potential method application at archaeological sites in Israel, Trans. of the EUG XI Intern. Symp., Strasbourg, France, p. 657, 2001a.

Eppelbaum, L., Ben-Avraham, Z., and Itkis, S.: Ancient Roman Remains in Israel provide a challenge for physical-archaeological modeling techniques, First Break, 21(2), 51-61, $2003 \mathrm{a}$.

Eppelbaum, L. V., Ben-Avraham, Z., and Itkis, S. E.: Integrated geophysical investigations at the Halutza archaeological site, Proceed. of the 64, EAGE Conf., Florence, Italy, P151, 4 pp., 2003b.

Eppelbaum, L. V., Ben-Avraham, Z., and Mishne, A.: Remote pilot vehicle survey and modern geophysical data interpretation, Trans. of the Conf. of the Israel Geol. Soc. Ann. Meet., Ma'alot, Israel, p. 36, 2000a.

Eppelbaum, V. M. and Eppelbaum, L. V.: Advanced approach to formalization and controlling of geological prospecting, Trans. of the Conf. of the Geological Soc. of America, Rocky Mountain, USA, 27(4), 10-11, 1995.

Eppelbaum, L., Eppelbaum, V., and Ben-Avraham, Z.: Formalization and estimation of integrated geological investigations: Informational approach, Geoinformatics, 14, 3, 233-240, 2003.

Eppelbaum, L. V., Ezersky, M., Al-Zoubi, A., Goldshmidt, V., and Legchenko, A.: Study of the factors affecting the karst volume assessment in the Dead Sea sinkhole problem using microgravity field analysis and 3-D modeling, Adv. Geosci., 19, 97-115, 2008, http://www.adv-geosci.net/19/97/2008/.

Eppelbaum, L. V. and Itkis, S. E.: Magnetic investigations in the Proto-Historic site to the east of Tel Megiddo, in: Monograph Series of the Inst. of Archaeology, edited by: I. Finkelstein, Ussishkin, D., and Halpern, B., Emery and Claire Yass Publications in Archaeology, Tel Aviv University, "Megiddo III", Monogr. Ser. No. 18, 504-514, 2000.

Eppelbaum, L. V. and Itkis, S. E.: Detailed magnetic investigations at the ancient Roman site Banias II (Northern Israel), Proceed. of the $1^{\text {st }}$ Intern Symp, on Soil and Archaeology, Szazhalombatta, Hungary, 13-16, 2001.

Eppelbaum, L. V. and Itkis, S. E.: Geophysical examination of the 
Christian archaeological site Emmaus-Nicopolis (central Israel), Collection of Papers of the XIX CIPA Conf. "New Perspectives to Save the Cultural Heritage", Antalya, Turkey, 395-400, 2003. Eppelbaum, L. V., Itkis, S. E., Fleckenstein, K.-H., and Fleckenstein L.: Latest results of geophysical-archaeological investigations at the Christian archaeological site Emmaus-Nicopolis (central Israel), Proceed. of the 69th EAGE Conference, P118, London, Great Britain, 5 pp., 2007.

Eppelbaum, L. V., Itkis, S. E., and Gopher, A.: Interpreting magnetic data at Nahal Zehora II, in: Archaeological investigations at the sites of Nahal-Zehora, Monograph Series of the Inst. of Archaeology, Emery and Claire Yass Publications, edited by: Gopher, A., Tel Aviv University, Monogr. Ser. No. 19, 2010a (in Press).

Eppelbaum, L. V., Itkis, S. E., and Khesin, B. E.: Optimization of magnetic investigations in the archaeological sites in Israel, in: Filtering, Modeling and Interpretation of Geophysical Fields at Archaeological Objects, Special Issue of Prospezioni Archeologiche, 65-92, 2000b.

Eppelbaum, L. V., Itkis, S. E., and Khesin, B. E.: Initial visualization of magnetic survey results at the Prehistoric archaeological sites in Israel, Proceed. of the 5th Intern. Symp. on Eastern Mediterranean Geology, Thessaloniki, Greece, 2, 747-750, 2004a.

Eppelbaum, L., Itkis, S., and Khesin, B.: Detailed magnetic survey unmasks Prehistoric archaeological sites in Israel, Proceed. of the Symp. on the Application of Geophysics to Engineering and Environmental Problems, Calgary, Canada, 1366-1373, 2006a.

Eppelbaum, L. V., Itkis, S. E., and Petrov, A. V.: Physics and archaeology: magnetic field as a reliable tool for searching ancient remains in Israel, Scientific Israel, 2, 68-78, 2000c.

Eppelbaum, L. V. and Khesin, B. E.: VLF-method: a new interpretation scheme and feasibility of its application in Israel, Trans. of the Conf. of Israel Geological Soc., Ann. Meeting. Zikhron Yakov, Israel, p. 24, 1995.

Eppelbaum, L. V. and Khesin, B. E.: Disturbing factors in geophysical investigations at archaeological sites and ways of their elimination, Trans. of the IV Conf. on Archaeological Prospection, Vienna, Austria, 99-101, 2001.

Eppelbaum, L. V., Khesin, B. E., and Itkis, S. E.: Prompt magnetic investigations of archaeological remains in areas of infrastructure development: Israeli experience, Archaeol. Prospect., 8(3), 163185, 2001b.

Eppelbaum, L. V., Khesin, B. E., and Itkis, S. E.: Some peculiarities of geophysical investigations at archaeological sites in Israel, Russian Archaeology, 1, 59-70, 2006b.

Eppelbaum, L. V., Khesin, B. E. and Itkis, S. E.: Archaeological geophysics in arid environments: Examples from Israel, J. Arid. Environ., 74(7), 849-860, 2010b.

Eppelbaum, L. V., Khesin, B. E., Itkis, S. E., and Ben-Avraham, Z.: Advanced analysis of self-potential data in ore deposits and archaeological sites, Proceed. of the 10th European Meeting of Environmental and Engineering Geophysics, Utrecht, The Netherlands, 4 pp., 2004b.

Eppelbaum, L.V., Kutasov, I.M., and Barak, G.: Ground surface temperature histories inferred from 15 boreholes temperature profiles: Comparison of two approaches, Earth Sci. Res. J., 10(1), 25-34, 2006c.

Ezersky, M., Goldman, M., Bar-Matthews, M., and Ayalon, A.:
Geoelectric investigations of the Soreq Cave area in Israel, Proceed. of the EEGS-ES Annual Meet., Bochum, Germany, PCD01, 2 pp., 2000.

Finkelstein, M. and Eppelbaum, L.: Classification of the disturbing objects using interpretation of low-intensive temporary magnetic variations, Trans. of the Conf. the Geological Society of America, Salt Lake City, 29(6), p. 326, 1997.

Finkelstein, M. and Eppelbaum, L.: A new laser magnetic field detector and its application in geophysics, Trans. of the Conference of Israel Geological Society, Annual Meeting, Mizpe-Ramon, Israel, p. 30, 1998.

Frumkin, A., Shimron, A., and Rosenbaum, J.: Radiometric dating of the Siloam Tunnel, Jerusalem, Letters to Nature, 425, 169171, 2003.

Ginzburg, A. and Levanon, A.: Direct current resistivity measurements in archaeology, Geoexploration, 15, 47-56, 1977.

Godfrey-Smith, D. I., Vaughan, K. B., Gopher, A., and Barkai, R.: Direct Luminescence Chronology of the Epipaleolithic Kebaran Site of Nahal Hadera V, Israel, Geoarchaeology, 18(4), 461-475, 2003.

Horowitz, A.: The Quaternary of Israel, Academic Press, NY, USA, 394 pp., 1979.

Itkis, S. E.: Magnetic susceptibility measurements of soil: A diagnostic tool for location of human activity areas, in: The Neolithic Site of Abu Ghosh: The 1995 Excavations, edited by: Khalaily, H. and Marder, O., Chapter 14, (IAA Reports 19), Jerusalem, 129-131, 2003.

Itkis, S. E. and Eppelbaum, L. V.: First results of magnetic prospecting application at the Prehistoric sites of Israel, Journal of the Prehistoric Society of Israel, 28, 177-187, 1998.

Itkis, S. E. and Eppelbaum, L. V.: Magnetic survey in the vicinity of the Paneas, In: (Ed. M. Hartal) Paneas: The Survey, the Aqueduct, the northern cemeteries and excavations in the northwestern Suburb, The Israel Antique Authority, Jerusalem, Israel, 143-151, 2009.

Itkis, S. E. and Eppelbaum, L. V.: Magnetic prospecting of archaeological targets in the vicinity of Area F, Megiddo, in: Emery and Claire Yass Publications in Archaeology, edited by: Finkelstein, I., "Megiddo-IV", Tel Aviv University, in press, 2010.

Itkis, S., Feinstein, S., and Khesin, B.: Archaeomagnetic provinces in Israel as a basis for magnetic prospecting of archaeological sites, Proceed. of the $14^{\text {th }}$ Near-Surface Europ. Meeting of Environmental and Engineering Geophysics, Krakow, Poland, 5 pp., 2008.

Itkis, S., Khesin, B., Eppelbaum, L., and Khalaily, H.: The Natufian site of Eynan (Hula valley, Northern Israel): Magnetic prospecting reveals new features, Israel J. Earth Sci., 52(3-4), 209-219, 2003.

Kamai, R. and Hatzor, Y. H.: Numerical analysis of block stone displacements in ancient masonry structures: A new method to estimate historic ground motions, Intern. Jour. for Numerical and Analytical Methods in Geomechanics, 32, 1321-1340, 2007.

Karcz, I. and Kafri, U.: Evaluation of supposed archaeoseismic damage in Israel, J. Archaeol. Sci., 5(3), 237-253, 1978.

Karcz, I., Kafri, U., and Meshel, Z.: Archaeological evidence for subrecent seismic activity along the Dead Sea-Jordan Rift, Nature, 269, 234-235, 1977.

Kempinski, A. and Reich, R. (Eds.): The Architecture of Ancient Israel, Israel Exploration Society, Jerusalem, Israel, 332 pp., 1992. 
Kenyon, K. M.: Archaeology in the Holy Land, Norton, NY, 360 pp., 1979.

Khesin, B. and Feinstein, S.: Phanerozoic rock magnetization in southern and central Israel, Israel J. Earth Sci., 54(2), 97-111, 2005.

Khesin, B. E., Alexeyev, V. V., and Eppelbaum, L. V.: Interpretation of Geophysical Fields in Complicated Environments, Kluwer Academic Publishers, Ser.: Modern Approaches in Geophysics, Boston, Dordrecht, London, 368 pp., 1996.

Khesin, B. E. and Eppelbaum, L. V.: The number of geophysical methods required for target classification: quantitative estimation, Geoinformatics, 8(1), 31-39, 1997.

Korjenkov, A. M. and Mazor, E.: Seismogenic origin of the ancient Avdat ruins, Negev Desert, Israel, Nat. Hazards, 18, 193-226, 1999.

Jeffery, K. G.: New generation grid for environmental science, Environ. Modell. Softw., 22, 281-287, 2007.

Jol, H. M., Broshi, M., and Eshel, H.: GPR investigations at Qumran, Israel: site of the Dead Sea Scrolls discovery, Proceed. of SPIE Conf., 4758, Santa-Barbara, USA, 125-129, 2003.

Jol, H. M., Bauman, P. D., Darawsha, M., Freund, R. A., Reeder, P., and Savage, C.: Where Jesus played and bathed? Preliminary results from geophysical surveys at the Cactus Coffee House, Mary's Well Plaza, Nazareth, Israel, Abstracts of the 5th Recent Work in Archaeological Geophysics Conf., Environ. and Industrial Geophysics Group, Geological Soc., Burlington House, London, UK, 15-16 December, 13-41, 2004.

Jol, H. M., Freund, R. A., Darawsha, M., Bauman, P. D., Nahas, S., Reeder, P., Savage, K., and Syon, D.: Nazareth excavations project: A GPR perspective, Proceed. of the Symp. on the Application of Geophysics to Engineering and Environmental Problems, Philadelphia, USA, 1407-1413, 2008.

Laukhin, S. S., Ronen, A., Pospelova, G. A., Sharonova, Z. V., Ranov, V. A., Burdukiewicz, J. M., Volgina, V. A., and Tsatskin, A.: New data on the geology and geochronology of the Lower Palaeolithic site Bizat Ruhama in the Southern Levant, Paleorient, 27(1), 69-80, 2001.

Marco, S.: Recognition of earthquake-related damage in archaeological sites: Examples from the Dead Sea fault zone, Tectonophysics, 453(1-4), 122-147, 2008.

Marco, S., Hartal, M., Hazan, N., Lev, L., and Stein, M.: Archaeology, history, and geology of the AD 749 earthquake, Dead Sea transform, Geology, 31(8), 665-668, 2003.

McDermott, F., Grün, R., Stringer, C. B., and Hawkesworth, C. J.: Mass-spectrometric U-series dates for Israeli Neanderthal/early modern human sites, Nature, 363, 252-255, 1993.

Meyers, E. M. (Ed.): The Oxford Encyclopedia of Archaeology in the Near East, 5, Oxford University Press, Oxford, UK, 1996.

Mindell, D. A. and Bingham, B.: A high-frequency, narrow-beam sub bottom profiler for archaeological applications, Proceed. of the IEEE Ocean Conf., 1-9, 2001.

Nahas, C., Bauman, P., Jol, H., Reeder, P., and Freund, R.: Geophysical investigations at coastal archaeological sites in Israel, Proceed. of the Symp. on the Application of Geophysics to Engineering and Environmental Problems, Seattle, Washington, 1397-1406, 2006.

Neishtadt, N. M., Eppelbaum, L. V., and Levitski, A. G.: Application of seismo-electric phenomena in exploration geophysics: Review of Russian and Israeli experience, Geophysics, 71(2),
B41-B53, 2006.

Nur, A. and Ron, H.: Armageddon's earthquake, Int. Geol. Rev., 39(6), 532-541, 1997.

Paparo, H.: Temperature surveying in the Gamla site, Trans. of the Conf. of Israel Geol. Soc., Annual Meeting, Mizpe Ramon, Israel, p. 100, 1987.

Paparo, H.: Temperature study of the archaeological site Crusades Fortress Um Haled (Netanya), Trans. of the Conf. of Israel Geol. Soc., Annual Meeting, Akko, Israel, p. 77, 1991.

Pelfer, P. G., Barcelo, J. A., McDonaill, C., and Pelfer, G.: ArchaeoGRID, a GRID for archaeology, Proceed. of the IEEE Nuclear Science Symp. Conf., 4, 2095-2099, 2004.

Pollard, A. M. and Bray, P.: A bicycle made for two? The integration of scientific techniques into archaeological interpretation, The Annual Review of Anthropology, 36, 245-259, 2007.

Porat, N., Zhou, L. P., Chazan, M., Noy, T., and Horwitz, L. K.: Dating the lower Paleolithic open-air site of Holon, Israel, by luminescence and ESR techniques, Quaternary Res., 51, 328341, 1999.

Reeder, P., Jol, H., Bauman, P., and Freund, R.: Multidisciplinary research at the Cave of Letters, Israel: a melding of physical and social sciences, Proceed. of Trans-Karst 2004 International Transdiscipl. Conf. on Development and Conservation of Karst Regions, Ha Noi, Vietnam, 181-184, 2004.

Reich, S., Leitus, G., and Shalev, S.: Measurement of corrosion content of archaeological lead artifacts by their Meissner response in the superconducting state; a new dating method, New J. Phys., 5, 991-999, 2003.

Rigaud, V.: Innovation and operation with robotized underwater systems, J. Field Robot., 24(6), 449-459, 2007.

Rink, W. J., Schwarcz, H. P., Lee, H. K., Rees-Jones, J., Rabinovich, R., and Hovers, E.: Electron Spin Resonance (ESR) and Thermal Ionization Mass Spectrometric (TIMS) 230Th/234U Dating of Teeth in Middle Paleolithic Layers at Amud Cave, Israel, Geoarchaeology, 16(6), 701-717, 2001.

Ron, H., Porat, N., Ronen, A., Tchernov, E., and Horwitz, L.: Magnetostratigraphy of the Evron Member - implications for the age of the Middle Acheulian site of Evron Quarry, J. Hum. Evol., 44, 633-639, 2003.

Segal, Y., Marco, S., and Ellenblum, R.: Intensity and direction of the geomagnetic field in 24 August, 1179 measured in Vadum Iacob (Ateret) Crusader Fortress, Northern Israel, Israel Jour. Earth Sci., 52, 203-208, 2003.

Shaar, R., Ron, H., Tauxe, L., Kessel, R., Agnon, A., Ben-Yosef, E., and Feinberg, J. M.: Testing the accuracy of absolute intensity estimates of the ancient geomagnetic field using copper slag material, Earth Planet. Sc. Lett., 290, 201-213, 2010.

Shalem, N.: Earthquakes in Jerusalem, Jerushalaim, 1, 22-54 (in Hebrew), 1949.

Sternberg, R. and Lass, E. H. E.: An archaeomagnetic study of two hearths from Kebara Cave, Israel, in: Kebara Cave, Mt. Carmel, Israel: The Middle and Upper Paleolithic Archaeology, Part I, American School of Prehistoric Research, edited by: Bar-Yosef, O. and Meignen, L., Bull., 49, Peabody Museum of Archaeology and Ethnology, Harvard University, Cambridge, 123-130, 2007.

Sternberg, R., Lass, E., Marion, E., Katari, K., and Holbrook, M.: Anomalous archaeomagnetic directions and site formation processes at archaeological sites in Israel, Geoarchaeology, 14(5), 415-439, 1999. 
Suggestions to authors of the reports of the United States Geological Survey, 6th edn.: Washington, US Government Publishing Office, 1978.

Tanzi, J. D., Vickers, R. S., and Burns, P. L.: Application of electrical resistivity techniques to archaeological surveys, Proceed. of the International Geoscience and Remote Sensing Symposium, $1-3,1983$.

Thomas, R.: An update on the Four-Color Theorem, Not. Amer. Math. Soc., 45(7), 848-859, 1998.

Treague, J. J., Jol, H. M., Fisher, T. G., Freund, R. A., Reeder, P., Savage, C., and Bauman, P. D.: Three-dimensional, subsurface GPR visualization for an archaeological site (Qumran, Israel) and a geomorphic site (Michigan), Proceed. of the Geol. Society of America, 39th Annual Meeting of the North-Central Section, Minneapolis, MN, 19-20 May, 37(5), 15 p., 2005.

Triola, M. F.: Essentials of Statics, 4th edn., Addison Wesley, 270 pp., 2007.

Valladas, H., Mercier, N., Froget, L., Hovers, E., Joron, J.-L., Kimber, W. H., and Rak, Y.: TL Dates for the Neanderthal Site of the Amud Cave, Israel, J. Archaeol. Sci., 26, 259-268, 1999.

Verri, G., Barkai, R., Bordeanu, C., Gopher, A., Hass, M., Kaufman, A., Kubik, P., Montanari, E., Paul, M., Ronen, A., Weiner, S., and Boaretto, E.: Flint mining in prehistory recorded by in situproduced cosmogenic ${ }^{10} \mathrm{Be}$, Proceed. of the National Academy of Sciences (USA), 101(21), 7880-7884, 2004.
Weinstein-Evron, M., Beck, A., and Ezersky, M.: Geophysical investigations in the service of Mount Carmel (Israel) prehistoric research, J. Archaeol. Sci., 30, 1331-1341, 2003.

Weinstein-Evron, M., Mart, Y., and Beck, A.: Geophysical investigations in the el-Wad Cave, Mt. Carmel, Israel, Geoarchaeology, 6, 355-365, 1991.

Weiner, S., Goldberg, P., and Bar-Yosef, O.: Bone preparation in Kebara cave, Israel using on-site Fourier-transform infrared spectrometry, J. Archaeol. Sci., 20, 613-627, 1993.

Weiss, E., Ginzburg, B., Cohen, T. R., Zafrir, H., Alimi, R., Salomonski, N., and Shatvit, J.: High resolution marine magnetic survey of shallow water littoral area, Sensors, 7, 1697-1712, 2007.

Willis, B.: Earthquakes in the Holy Land, Bull. of Seismol. Soc. of America, 18, 73-103, 1928.

Witten, A. J., Levy, T. E., Ursic, J., and White, P.: Geophysical diffraction tomography: New views on the Shiqmim prehistoric subterranean village site (Israel), Geoarchaeology, 10(2), 97$118,1995$. 